\title{
THE
}

2003

\section{Springtime photochemistry at northern mid and high latitudes}

Yuhang Wang

Brian Ridley

Alan Fried

Christopher Cantrell

Douglas Davis

See next page for additional authors

Follow this and additional works at: https://digitalcommons.uri.edu/gsofacpubs

Terms of Use

All rights reserved under copyright.

\section{Citation/Publisher Attribution}

Wang, Y., et al. (2003), Springtime photochemistry at northern mid and high latitudes, J. Geophys. Res., 108, 8358, doi: 10.1029/2002JD002227, D4.

Available at: https://doi.org/10.1029/2002JD002227

This Article is brought to you for free and open access by the Graduate School of Oceanography at DigitalCommons@URI. It has been accepted for inclusion in Graduate School of Oceanography Faculty Publications by an authorized administrator of DigitalCommons@URI. For more information, please contact digitalcommons-group@uri.edu. 


\section{Authors}

Yuhang Wang, Brian Ridley, Alan Fried, Christopher Cantrell, Douglas Davis, Gao Chen, Julie Snow, Brian G. Heikes, Robert Talbot, Jack Dibb, Frank Flocke, Andrew Weinheimer, Nicola Blake, Donald Blake, Richard Shetter, Barry Lefer, Elliot Atlas, Michael Coffey, Jim Walega, and Brian Wert 


\title{
Springtime photochemistry at northern mid and high latitudes
}

\author{
Yuhang Wang, ${ }^{1}$ Brian Ridley, ${ }^{2}$ Alan Fried, ${ }^{2}$ Christopher Cantrell, ${ }^{2}$ Douglas Davis, ${ }^{1}$ \\ Gao Chen, ${ }^{1}$ Julie Snow, ${ }^{3}$ Brian Heikes, ${ }^{3}$ Robert Talbot, ${ }^{4}$ Jack Dibb, ${ }^{4}$ Frank Flocke, ${ }^{2}$ \\ Andrew Weinheimer, ${ }^{2}$ Nicola Blake, ${ }^{5}$ Donald Blake, ${ }^{5}$ Richard Shetter, ${ }^{2}$ Barry Lefer, ${ }^{2}$ \\ Elliot Atlas, ${ }^{2}$ Michael Coffey, ${ }^{2}$ Jim Walega, ${ }^{2}$ and Brian Wert ${ }^{2}$
}

Received 22 February 2002; revised 21 May 2002; accepted 18 June 2002; published 23 January 2003.

[1] Physical and chemical properties of the atmosphere at $0-8 \mathrm{~km}$ were measured during the Tropospheric Ozone Production about the Spring Equinox (TOPSE) experiments from February to May 2000 at mid $\left(40^{\circ}-60^{\circ} \mathrm{N}\right)$ and high latitudes $\left(60^{\circ}-80^{\circ} \mathrm{N}\right)$. The observations were analyzed using a diel steady state box model to examine $\mathrm{HO}_{x}$ and $\mathrm{O}_{3}$ photochemistry during the spring transition period. The radical chemistry is driven primarily by photolysis of $\mathrm{O}_{3}$ and the subsequent reaction of $\mathrm{O}\left({ }^{1} \mathrm{D}\right)$ and $\mathrm{H}_{2} \mathrm{O}$, the rate of which increases rapidly during spring. Unlike in other tropospheric experiments, observed $\mathrm{H}_{2} \mathrm{O}_{2}$ concentrations are a factor of 2-10 lower than those simulated by the model. The required scavenging timescale to reconcile the model overestimates shows a rapid seasonal decrease down to $0.5-1$ day in May, which cannot be explained by known mechanisms. This loss of $\mathrm{H}_{2} \mathrm{O}_{2}$ implies a large loss of $\mathrm{HO}_{x}$ resulting in decreases in $\mathrm{O}_{3}$ production $(10-20 \%)$ and $\mathrm{OH}$ concentrations $(20-30 \%)$. Photolysis of $\mathrm{CH}_{2} \mathrm{O}$, either transported into the region or produced by unknown chemical pathways, appears to provide a significant $\mathrm{HO}_{x}$ source at $6-8 \mathrm{~km}$ at high latitudes. The rapid increase of in situ $\mathrm{O}_{3}$ production in spring is fueled by concurrent increases of the primary $\mathrm{HO}_{x}$ production and NO concentrations. Long-lived reactive nitrogen species continue to accumulate at mid and high latitudes in spring. There is a net loss of $\mathrm{NO}_{x}$ to $\mathrm{HNO}_{3}$ and PAN throughout the spring, suggesting that these long-term $\mathrm{NO}_{x}$ reservoirs do not provide a net source for $\mathrm{NO}_{x}$ in the region. In situ $\mathrm{O}_{3}$ chemical loss is dominated by the reaction of $\mathrm{O}_{3}$ and $\mathrm{HO}_{2}$, and not that of $\mathrm{O}\left({ }^{1} \mathrm{D}\right)$ and $\mathrm{H}_{2} \mathrm{O}$. At midlatitudes, there is net in situ chemical production of $\mathrm{O}_{3}$ from February to May. The lower free troposphere $(1-4 \mathrm{~km})$ is a region of significant net $\mathrm{O}_{3}$ production. The net production peaks in April coinciding with the observed peak of column $\mathrm{O}_{3}(0-8 \mathrm{~km})$. The net in situ $\mathrm{O}_{3}$ production at midlatitudes can explain much of the observed column $\mathrm{O}_{3}$ increase, although it alone cannot explain the observed April maximum. In contrast, there is a net in situ $\mathrm{O}_{3}$ loss from February to April at high latitudes. Only in May is the in situ $\mathrm{O}_{3}$ production larger than loss. The observed continuous increase of column $\mathrm{O}_{3}$ at high latitudes throughout the spring is due to transport from other tropospheric regions or the stratosphere not in situ photochemistry. INDEX TERMS: 0317 Atmospheric Composition and Structure: Chemical kinetic and photochemical properties; 0322 Atmospheric Composition and Structure: Constituent sources and sinks; 0365 Atmospheric Composition and Structure: Troposphere-composition and chemistry; 0368 Atmospheric Composition and Structure: Troposphere - constituent transport and chemistry; KEYWORDS: springtime, ozone, $\mathrm{HO}_{\mathrm{x}}$, oxidation, reactive nitrogen

Citation: Wang, Y., et al., Springtime photochemistry at northern mid and high latitudes, J. Geophys. Res., 108(D4), 8358, doi:10.1029/2002JD002227, 2003.

\footnotetext{
${ }^{1}$ School of Earth and Atmospheric Sciences, Georgia Institute of Technology, Atlanta, Georgia, USA.

${ }^{2}$ National Center for Atmospheric Research, Boulder, Colorado, USA.

${ }^{3}$ Graduate School of Oceanography, University of Rhode Island, Narragansett, Rhode Island, USA.

${ }^{4}$ Institute for the Study of Earth, Oceans, and Space, University of New Hampshire, Durham, New Hampshire, USA.

${ }^{5}$ Department of Chemistry, University of California at Irvine, Irvine, California, USA.
}

Copyright 2003 by the American Geophysical Union. 0148-0227/03/2002JD002227

\section{Introduction}

[2] Oxidation processes in the troposphere are important pathways that mitigate the effects of human activities on the environment. These processes are intertwined in a tightly coupled photochemical system that involves among others $\mathrm{HO}_{x}\left(\mathrm{OH}+\mathrm{HO}_{2}\right), \mathrm{O}_{3}, \mathrm{NO}_{x}\left(\mathrm{NO}+\mathrm{NO}_{2}\right), \mathrm{CO}$, and hydrocarbons. Spring at northern mid and high latitudes is a particularly interesting and challenging time to study the system because of the rapidly changing photochemical environment driven in part by increasing solar insolation. 
[3] Previous understanding for the spring period is largely based on surface measurements and ozonesondes. Logan [1985] showed on the basis of ozonesonde measurements a ubiquitous springtime $\mathrm{O}_{3}$ maximum in the lower troposphere at remote northern mid and high latitude sites. The springtime $\mathrm{O}_{3}$ maximum at rural sites is in contrast to the summertime $\mathrm{O}_{3}$ maximum at polluted sites. Two factors have been attributed to the observed springtime ozone maximum, $\mathrm{O}_{3}$ transport from the stratosphere [Logan, 1985; Levy et al., 1985] and $\mathrm{O}_{3}$ production within the troposphere [Penkett and Brice, 1986; Liu et al., 1987]. Measurements in the Swiss Alps (at an altitude of $3.6 \mathrm{~km}$ ) from the Free Tropospheric Experiment (FREETEX'96 and 98) suggested that the net in situ chemical production of $\mathrm{O}_{3}$ contributes significantly to the observed spring-summer maximum in the region [Carpenter et al., 2000; Zanis et al., 2000]. Among global 3-D modeling studies of tropospheric $\mathrm{O}_{3}$, Wang et al. [1998] and Yienger et al. [1999] investigated in detail the sources of the observed springtime $\mathrm{O}_{3}$ maximum. While the former study showed that both factors contributed to the simulated springtime $\mathrm{O}_{3}$ maximum with one peaking in early spring and the other peaking in early summer, the latter study emphasized the effect of net $\mathrm{O}_{3}$ chemical production at midlatitudes. Possible accumulation of pollutants at high latitudes in winter [Honrath and Jaffe, 1992; Jobson et al., 1994; Novelli et al., 1994; Bottenheim and Shepherd, 1995; Honrath et al., 1996] may also enhance photochemistry in spring at mid and high latitudes.

[4] The Tropospheric Ozone Production about the Spring Equinox (TOPSE) experiment took place in February-May 2000 (E. Atlas et al., The TOPSE experiment: Introduction, submitted to Journal of Geophysical Research, 2002, hereinafter referred to as Atlas et al., submitted manuscript, 2002). Forty two C-130 flights (including 4 test flights) in between Jeffco, Winnipeg, Churchill, and Thule were conducted in 7 deployments, 1-2 weeks apart. A broad suite of in situ measurements of meteorological parameters, trace gases, and aerosols were made from near the surface up to 8 $\mathrm{km}$. The seasonal span of the experiment allows for analyzing the springtime evolution of photochemistry at northern mid and high latitudes.

[5] We describe in section 2 the model and data processing procedures used in this work. In section 3 we examine various aspects of $\mathrm{HO}_{x}$ chemistry. Contributions of primary $\mathrm{HO}_{x}$ production and $\mathrm{NO}_{x}$ concentrations to in situ $\mathrm{O}_{3}$ production are investigated in section 4 . Budgets of reactive nitrogen and $\mathrm{O}_{3}$ are studied in section 5 to explore the sources of observed $\mathrm{O}_{3}$ and $\mathrm{NO}_{x}$. We summarize our findings in section 6 .

\section{Model Description and Data Processing}

[6] A box model is applied in the analysis of in situ photochemistry. The model has been used previously in analyzing observations from other aircraft missions [Davis et al., 1996, 2001; Crawford et al., 1997, 1999; Chen et al., 2001]. The kinetics data for $\mathrm{O}_{3}-\mathrm{NO}_{x}$-CO-hydrocarbon reactions are taken from DeMore et al. [1997] and Atkinson et al. [1997]. Crawford et al. [1999] listed the reaction rate constants used in the model. Photolysis rate coefficients are first computed using the DISORT 4-stream NCAR Tropospheric
Ultraviolet-Visible (TUV) radiative transfer code (by S. Madronich). The quantum yield and absorption crosssection data are those reported by DeMore et al. [1997]; the quantum yield of $\mathrm{O}\left({ }^{1} \mathrm{D}\right)$ is from Talukdar et al. [1998]. The photolysis rates are then constrained by the observed $\mathrm{J}$ values [Shetter et al., 2002] to account for cloud and surface reflectivity.

[7] The model is constrained by the observations of $\mathrm{O}_{3}$, $\mathrm{NO}, \mathrm{CO}$, nonmethane hydrocarbons (NMHCs), temperature, and water vapor. Concentrations of $\mathrm{H}_{2} \mathrm{O}_{2}, \mathrm{CH}_{3} \mathrm{OOH}$, and $\mathrm{CH}_{2} \mathrm{O}$ are constrained in some simulations (see figure captions for details). All model parameters except NO and photolysis rates are held constant in multiple-day runs. The concentrations of $\mathrm{NO}_{x}\left(\mathrm{NO}+\mathrm{NO}_{2}\right)$ are held at constant values that give the observed $\mathrm{NO}$ concentrations at the time of the observation. The model converges and results are reported when the diurnal cycles of calculated concentrations do not vary from day to day.

[8] Measurement techniques and related data issues are discussed in the companioning papers in the special issue (see Atlas et al. (submitted manuscript, 2002) for a guide). The 1-min merged data file (courtesy of L. Emmons) is used except the data for $\mathrm{CH}_{2} \mathrm{O}$. The updated data [Fried et al., 2002], where the interference from $\mathrm{CH}_{3} \mathrm{OH}$ was removed, are used. Observations that show the imprints of $\mathrm{Br}$ and $\mathrm{Cl}$ chemistry are removed by eliminating data points with $\mathrm{O}_{3}$ concentrations $<20 \mathrm{ppbv}$ or depleted $\mathrm{C}_{2} \mathrm{H}_{2}$ relative to benzene [Jobson et al., 1994]; these data were found at altitudes of $<1 \mathrm{~km}$ above the surface. Data points with $\mathrm{O}_{3}$ concentrations $>100 \mathrm{ppbv}$ are also eliminated to remove the influence of stratospheric air masses.

[9] Concentrations of $\mathrm{CO}$ were measured with two different instruments. The whole air samples were collected and analyzed later using gas chromatographic apparatus [Blake et al., 2002] (hereafter UCI CO). The sampling frequency is 1-5 min. A fast-response $1 \mathrm{~Hz}$ tunable diode laser system from NCAR (hereafter NCAR CO) was also employed. The sensitivity of the instrument is about 1 ppbv for the 30-sec averages reported. Measurements of this instrument are in good agreement with limited whole air canister samples analyzed by gas chromatography at NCAR (M. T. Coffey, personal communication, 2001). However, the UCI CO data are on average 8 ppbv lower than NCAR CO measurements. The root mean square of the difference is $14 \mathrm{ppbv}$. The reasons for the discrepancies between the two measurements are unclear. In our analysis, we use both measurements to increase the available pool of measured data. When both measurements are available, averages are used.

[10] Acetone was not measured during TOPSE. We applied the observed acetone-CO correlations during the SONEX experiment [Singh et al., 2000]. A least squares fit of SONEX observations at 2-7 km gives [acetone] $=8+$ $6.8([\mathrm{CO}]-10)$, where acetone is in pptv and $\mathrm{CO}$ is in ppbv. NMHCs and $\mathrm{CO}$ were measured using the whole air samples [Blake et al., 2002]. The relatively low sampling frequency of NMHCs reduced the available data points by half in the photochemical analysis. We made use of the faster-response NCAR $\mathrm{CO}$ measurements to estimate NMHC concentrations in a similar manner as in estimating acetone concentrations. We first find the least squares fits of NMHCs to NCAR CO and then interpolate NMHC con- 
centrations for the NCAR CO data that do not overlap with the NMHC measurements. The fitting and interpolation are conducted for each month in two regions $\left(40^{\circ}-60^{\circ} \mathrm{N}\right.$ and $60^{\circ}-80^{\circ} \mathrm{N}$ ) for each $2-\mathrm{km}$ altitude bin from 0 to $8 \mathrm{~km}$ since much of our analysis in the following sections focuses on the monthly and regional characteristics. The procedure doubles the availability of measurement points, providing better statistical significance of the median values of key variables discussed in the following sections. The uncertainties introduced in these procedures will be taken into account in the analysis.

\section{Odd Hydrogen}

[11] Hydroxyl radicals are central to oxidation chemistry in the troposphere. Their chemical cycles are intrinsically connected to those of $\mathrm{O}_{3}$. Carbon monoxide, $\mathrm{CH}_{4}$, and NMHCs are oxidized by $\mathrm{OH}$ and peroxy radicals are produced. Peroxy radicals are recycled back to $\mathrm{OH}$ by $\mathrm{NO}$, which is oxidized to $\mathrm{NO}_{2}$. The oxidation cycle leads to $\mathrm{O}_{3}$ production by $\mathrm{NO}_{2}$ photolysis. Generally speaking, higher concentrations of $\mathrm{O}_{3}$ and $\mathrm{NO}$ tend to increase $\mathrm{OH}$ concentrations and higher concentrations of $\mathrm{CO}$ and hydrocarbons tend to decrease $\mathrm{OH}$ concentrations. Figure 1 shows the observed monthly median profiles of $\mathrm{O}_{3}, \mathrm{NO}, \mathrm{C}_{2} \mathrm{H}_{2}$, and $\mathrm{CO}$ for mid $\left(40^{\circ}-60^{\circ} \mathrm{N}\right)$ and high latitudes $\left(60^{\circ}-80^{\circ} \mathrm{N}\right)$. Median concentrations of $\mathrm{O}_{3}$ are comparable between mid and high latitudes. The increase of $10-30$ ppbv $\mathrm{O}_{3}$ from February to May is more pronounced at high latitudes. Concentrations of $\mathrm{NO}$ are much higher at midlatitudes, where the seasonal increase is about a factor of $2(10-30$ pptv); the seasonal increase of $\mathrm{NO}$ at high latitudes is a factor of 3-5 (about $10 \mathrm{pptv}$ ). In comparison, concentrations of $\mathrm{C}_{2} \mathrm{H}_{2}$ show a large seasonal decrease by a factor of 2-3 from February to May. This decrease was also observed for the concentrations of other NMHCs. There is a general decreasing trend for $\mathrm{CO}$; however the trend is much smaller than that of $\mathrm{C}_{2} \mathrm{H}_{2}$, reflecting in part that photochemistry is both a source and sink for $\mathrm{CO}$ but only a sink for NMHCs. The dichotomy in the seasonal trends of $\mathrm{O}_{3}$ and $\mathrm{NO}$ as compared to those of NMHCs and $\mathrm{CO}$ signifies the rapid increase of photochemical activity in springtime.

[12] Figure 2 shows simulated monthly median profiles of 24-hour average $\mathrm{OH}$ at mid and high latitudes. The model is constrained by observed peroxide concentrations. Only model results are shown because available $\mathrm{OH}$ measurements are limited to altitudes below $3 \mathrm{~km}$ and the overlapping measurement and simulation data points are few. The concentrations of $\mathrm{OH}$ increase significantly through the spring. Their values at high latitudes are significantly less than at midlatitudes reflecting in part the regional difference in solar irradiance and NO concentrations.

[13] Observed and simulated concentrations of total peroxy radicals $\left(\mathrm{RO}_{2}=\mathrm{HO}_{2}+\right.$ organic peroxy radicals $)$ show a similar seasonal trend as $\mathrm{OH}$ (Figure 3). Simulated $\mathrm{RO}_{2}$ concentrations are generally in good agreement with the observations although the model results are too high at midlatitudes in March. Among peroxy radicals, $\mathrm{HO}_{2}$ and $\mathrm{CH}_{3} \mathrm{O}_{2}$ are the major components. Detailed analysis of peroxy radical chemistry is carried out by Cantrell et al. [2002]. Comparison between simulated and observed $\mathrm{HO}_{2}$ concentrations is not made since $<20$ observational data points are available.

\subsection{Slowdown of $\mathrm{HO}_{x}$ Cycles: Heterogeneous Loss of $\mathrm{H}_{2} \mathrm{O}_{2}$}

[14] We use the model to examine the cycling of odd hydrogen. The largest primary source of $\mathrm{HO}_{x}$ in the troposphere is by photolysis of $\mathrm{O}_{3}$ and the subsequent reaction of $\mathrm{O}\left({ }^{1} \mathrm{D}\right)$ and $\mathrm{H}_{2} \mathrm{O}$ [Logan et al., 1981]. This source is considered a primary source because its magnitude is largely independent of the $\mathrm{HO}_{x}$ cycling. In comparison, $\mathrm{H}_{2} \mathrm{O}_{2}$, $\mathrm{CH}_{3} \mathrm{OOH}$, and other peroxides are produced chemically from the reaction of $\mathrm{HO}_{2}$ and another peroxy radical, both of which are produced during $\mathrm{OH}$ oxidation of $\mathrm{CO}$ and hydrocarbons. Their photolysis cycles peroxides back to $\mathrm{HO}_{x}$ and provides large $\mathrm{HO}_{x}$ sources. They are generally considered secondary $\mathrm{HO}_{x}$ sources because of their large dependence on $\mathrm{OH}$ oxidation. Photolysis of $\mathrm{CH}_{2} \mathrm{O}$ is generally considered a secondary source because $\mathrm{CH}_{2} \mathrm{O}$ is largely produced from hydrocarbon oxidation, whereas photolysis of acetone is generally a primary source [McKeen et al., 1997].

[15] Figure 4 shows the seasonal profiles of main $\mathrm{HO}_{x}$ sources (24-hour averages) at mid and high latitudes. The three dominant $\mathrm{HO}_{x}$ sources are $\mathrm{O}\left({ }^{1} \mathrm{D}\right)+\mathrm{H}_{2} \mathrm{O}$ and photolysis of $\mathrm{CH}_{2} \mathrm{O}$ and $\mathrm{CH}_{3} \mathrm{OOH}$. The latter two sources are particularly important at high altitudes. The large seasonal increase in the rate of $\mathrm{O}\left({ }^{1} \mathrm{D}\right)+\mathrm{H}_{2} \mathrm{O}$ is due the increase of solar insolation, $\mathrm{O}_{3}$ concentrations (Figure 1), and $\mathrm{H}_{2} \mathrm{O}$ content of the atmosphere (not shown). The last factor is associated with the seasonal warming of the atmosphere, which increases the saturation vapor pressure. We will show that most of $\mathrm{CH}_{2} \mathrm{O}$ and $\mathrm{CH}_{3} \mathrm{OOH}$ concentrations are produced by in situ photochemistry. Therefore these two photolysis sources are largely secondary. As a result, the activation of photochemistry in early spring at midlatitudes and in late spring at high latitudes, as evidenced in the seasonal increase of $\mathrm{OH}$ and $\mathrm{RO}_{2}$ concentrations (Figures 2 and 3 ), is largely driven by the radical source of $\mathrm{O}_{3}$ photolysis followed by the reaction of $\mathrm{O}\left({ }^{1} \mathrm{D}\right)$ and $\mathrm{H}_{2} \mathrm{O}$.

[16] The relatively large $\mathrm{HO}_{x}$ source from $\mathrm{CH}_{3} \mathrm{OOH}$ photolysis stands in sharp contrast to the much smaller source from $\mathrm{H}_{2} \mathrm{O}_{2}$ photolysis. The contrast can be seen more clearly in the comparison of observed and simulated peroxide concentrations. Figure 5 compares observed and simulated $\mathrm{H}_{2} \mathrm{O}_{2}$ monthly median profiles at mid and high latitudes. Simulated $\mathrm{H}_{2} \mathrm{O}_{2}$ concentrations are a factor of $2-$ 10 higher than the observations; the overestimates increase with decreasing altitude. In comparison, Figure 6 shows that simulated $\mathrm{CH}_{3} \mathrm{OOH}$ concentrations are generally in agreement with the observations. Using the rate constant of the $\mathrm{HO}_{2}$ self reaction suggested recently by Christensen et al. [2002], we find that simulated $\mathrm{H}_{2} \mathrm{O}_{2}$ concentrations decrease by $20-30 \%$ at $6-8 \mathrm{~km}$ and $5-15 \%$ at $0-4 \mathrm{~km}$; the large model overestimates remain. The new rate constant has little effects on simulated $\mathrm{OH}$ and $\mathrm{HO}_{2}$ concentrations.

[17] The measurement-model agreement of $\mathrm{CH}_{3} \mathrm{OOH}$ at midlatitudes is, however, not as good as those found in the tropics [Wang et al., 2000, 2001]. Particularly noteworthy is that simulated $\mathrm{CH}_{3} \mathrm{OOH}$ profiles have a consistent tendency of decreasing with altitude, which is in accordance with the observed profiles of $\mathrm{RO}_{2}$ concentrations (Figure 3). The observed $\mathrm{CH}_{3} \mathrm{OOH}$ profiles, however, show this altitude 

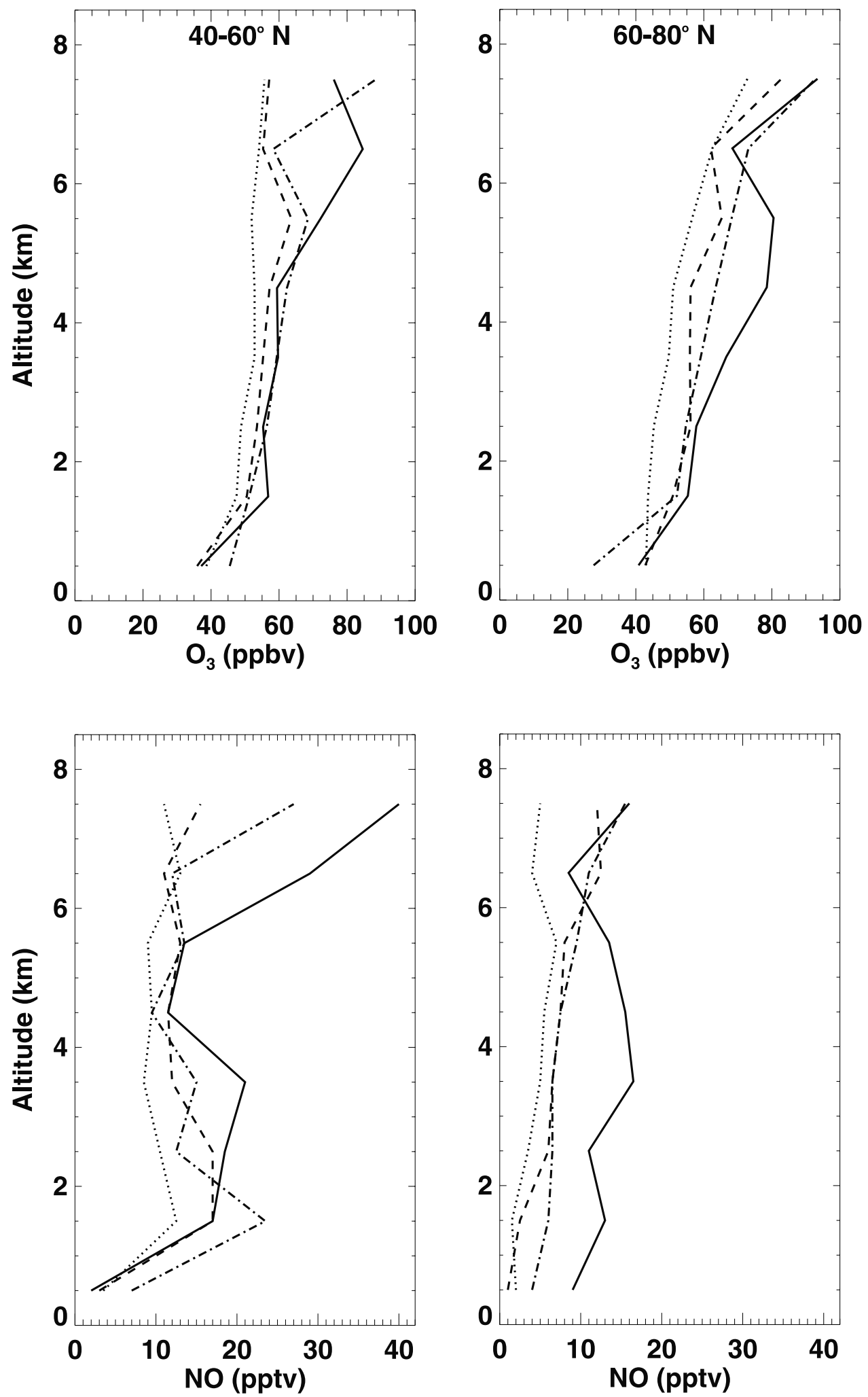

Figure 1. Monthly median profiles of observed $\mathrm{O}_{3}, \mathrm{NO}, \mathrm{C}_{2} \mathrm{H}_{2}$, and $\mathrm{CO}$ concentrations at mid $\left(40^{\circ}-\right.$ $\left.60^{\circ} \mathrm{N}\right)$ and high latitudes $\left(60^{\circ}-80^{\circ} \mathrm{N}\right)$. Data are binned vertically in $1-\mathrm{km}$ intervals. A median value plotted represents a minimum of 10 data points.

dependence in some months but not in others. In particular, the observed profile at midlatitudes in March shows increasing concentrations with altitude, opposite to the trend simulated in the model, resulting in large discrepancies between observed and simulated values. The model underestimate at $5-8 \mathrm{~km}$ is particularly large considering that the model overestimates peroxy radical concentrations in that month (Figure 3). The photochemical lifetime of $\mathrm{CH}_{3} \mathrm{OOH}$ 

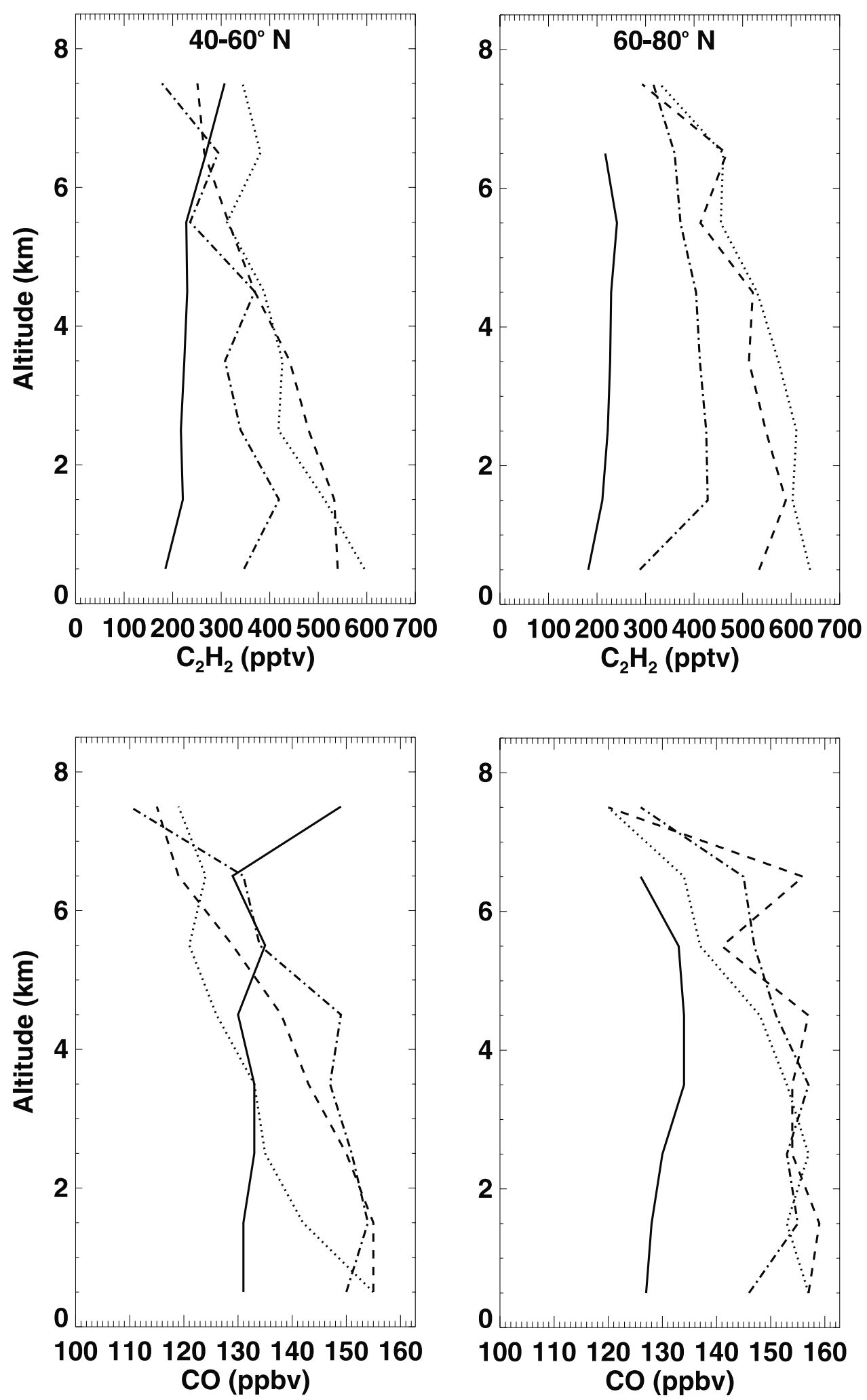

Figure 1. (continued)

is generally several weeks or longer during TOPSE. We examined the 10-day backtrajectories (courtesy of A. Wimmers and J. Moody). Above $4 \mathrm{~km}$, the general flow is controlled by strong westerlies. Some enhancements of $\mathrm{CH}_{3} \mathrm{OOH}$ are possible in the upper troposphere due to vertical transport in the upstream regions [e.g., Prather and Jacob, 1997]. Wang et al. [2001] estimated that the convective enhancement of $\mathrm{CH}_{3} \mathrm{OOH}$ over the tropical Pacific during PEM-Tropics B is only 50-150 pptv (above $10 \mathrm{~km}$ ) despite the short convective turnover timescale of 10 days. 

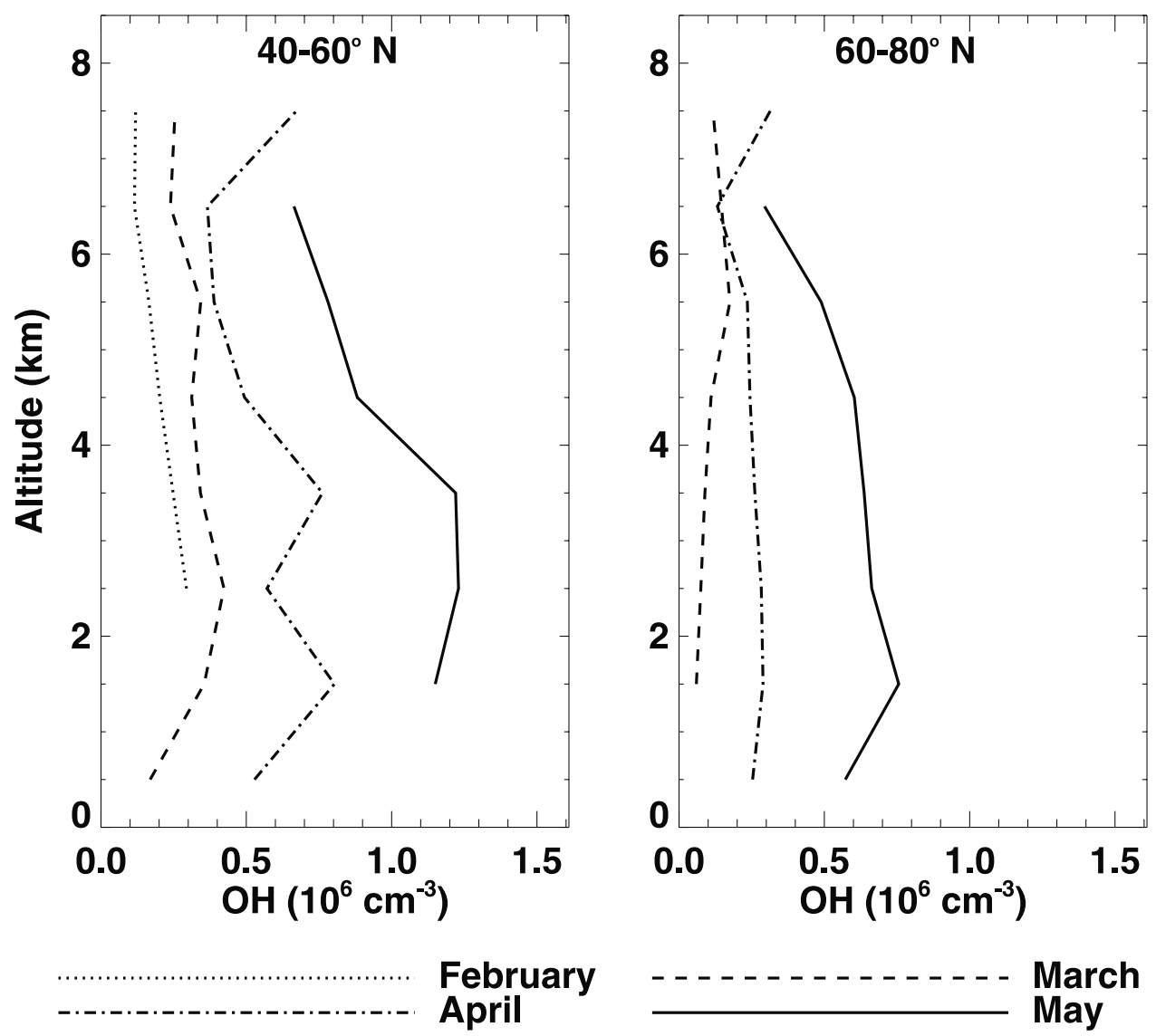

Figure 2. Same as Figure 1 but for simulated 24-hour average $\mathrm{OH}$ concentrations at mid and high latitudes. The model was constrained by observed peroxide concentrations.

The concentration of $\mathrm{CH}_{3} \mathrm{OOH}$ in the tropical marine boundary is about 1 ppbv. In that work, concentrations of $\mathrm{CH}_{3} \mathrm{OOH}$ are lowered by up to $100 \mathrm{pptv}$ at $4-7 \mathrm{~km}$ due in part to the subsidence of lower concentrations from higher altitudes. Considering that boundary layer $\mathrm{CH}_{3} \mathrm{OOH}$ concentrations in the TOPSE region are only 200-300 pptv, the likely source for high $\mathrm{CH}_{3} \mathrm{OOH}$ air masses to the region is from convective transport over the Pacific. The backtrajectory analysis shows, however, flow patterns in April and May similar to that in March. We also examined other chemical tracers but did not find clear signals implicating strong influence by marine air masses in March. The overestimates at $0-4 \mathrm{~km}$ may reflect peroxy radical depletion by fresh NO emissions in the upstreamflow from western United States and Canada. A chemistry and transport model will be necessary to explore further the causes for the observed vertical trend of $\mathrm{CH}_{3} \mathrm{OOH}$ at midlatitudes in March.

[18] At first glance, the large overestimates of $\mathrm{H}_{2} \mathrm{O}_{2}$ concentrations but not $\mathrm{CH}_{3} \mathrm{OOH}$ might be due to wet scavenging, which efficiently removes soluble $\mathrm{H}_{2} \mathrm{O}_{2}$ but not $\mathrm{CH}_{3} \mathrm{OOH}$. Wang et al. [2001] showed convective scavenging over the tropical Pacific decreases $\mathrm{H}_{2} \mathrm{O}_{2}$ concentrations by about $30 \%$. Estimating the magnitude of wet scavenging on the basis of meteorological measurements during TOPSE is difficult. Instead we compare the degree of heterogeneous loss of two soluble tracers, $\mathrm{H}_{2} \mathrm{O}_{2}$ and $\mathrm{HNO}_{3}$. Concentrations of $\mathrm{HNO}_{3}$ are also overestimated in the model (not shown). Figure 7 shows the seasonal progression of photochemical lifetimes of the two species through the spring at mid and high latitudes. The photochemical lifetimes are getting shorter into the summer because of increasing photochemical activity. The photochemical lifetime of $\mathrm{HNO}_{3}$ is generally about a factor 10 longer than $\mathrm{H}_{2} \mathrm{O}_{2}$. Furthermore, the solubility of $\mathrm{HNO}_{3}$ is higher than $\mathrm{H}_{2} \mathrm{O}_{2}$, making $\mathrm{HNO}_{3}$ concentrations more sensitive to wet scavenging and deposition loss.

[19] Assuming gas phase oxidation (by $\mathrm{OH}$ ), photolysis, and scavenging are the pathways for removal of $\mathrm{H}_{2} \mathrm{O}_{2}$ and $\mathrm{HNO}_{3}$, we calculate the scavenging timescales necessary to match the observed concentrations in the model (Figure 8). The required timescales for $\mathrm{HNO}_{3}$ scavenging are consistent with known rainout frequency and high solubility of $\mathrm{HNO}_{3}$. The required scavenging is much faster at midlatitudes than at high latitudes, reflecting more frequent rainout at midlatitudes. The general trend of decreasing scavenging with altitude is also consistent with the distribution of rainout. The timescales of $\mathrm{HNO}_{3}$ against scavenging loss are about 1 week at midlatitudes and 2-4 weeks at high latitudes. Our estimates of $\mathrm{HNO}_{3}$ scavenging timescale are likely the upper limits since we do not take into account the heterogeneous production of $\mathrm{HNO}_{3}$ by $\mathrm{N}_{2} \mathrm{O}_{5}$ hydrolysis on aerosols, which could be significant particularly at midlatitudes [Tie et al., 2002]. Nonetheless, the derived timescales are in line with the estimates derived from a global 3-D study of the observed ${ }^{210} \mathrm{~Pb}$ distributions by Balkanski et al. [1993].

[20] The required timescales of $\mathrm{H}_{2} \mathrm{O}_{2}$ scavenging are more difficult to understand. First, the required scavenging 

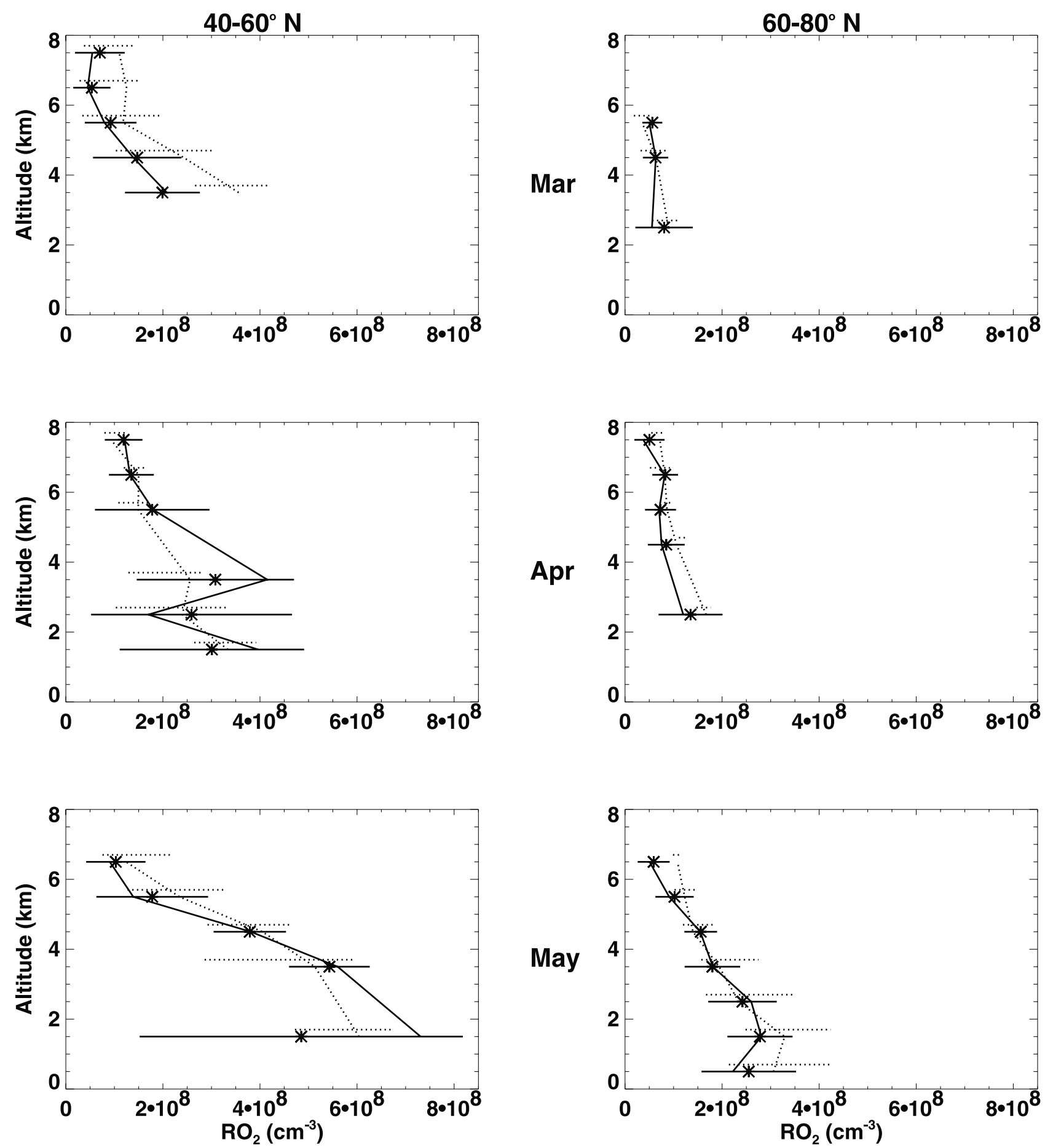

Figure 3. Monthly median profiles of observed and simulated total peroxy radicals $\left(\mathrm{RO}_{2}\right)$ at mid and high latitudes. The solid vertical lines show the observed medians in 1-km intervals. The solid horizontal lines and asterisks are the observed standard deviations and means, respectively. Simulated medians and standard deviations are shown in dashed lines. Model calculations are constrained by observed peroxide concentrations. Each observation data point has a corresponding simulated value and vice versa. A median value plotted represents a minimum of 10 data points. Not enough data are available for February.

frequency of $\mathrm{H}_{2} \mathrm{O}_{2}$ is up to a factor of 10 faster than that of $\mathrm{HNO}_{3}$. In May, the loss by scavenging is about half a day at midlatitudes and 1 day at high latitudes. Second, the required scavenging frequency of $\mathrm{H}_{2} \mathrm{O}_{2}$ is more seasonal than that of $\mathrm{HNO}_{3}$. The seasonal increase of the former is about a factor of 5 at mid and high latitudes. In contrast, the scavenging frequency of $\mathrm{HNO}_{3}$ shows no clear seasonal change at midlatitudes and a much smaller increase (mostly 

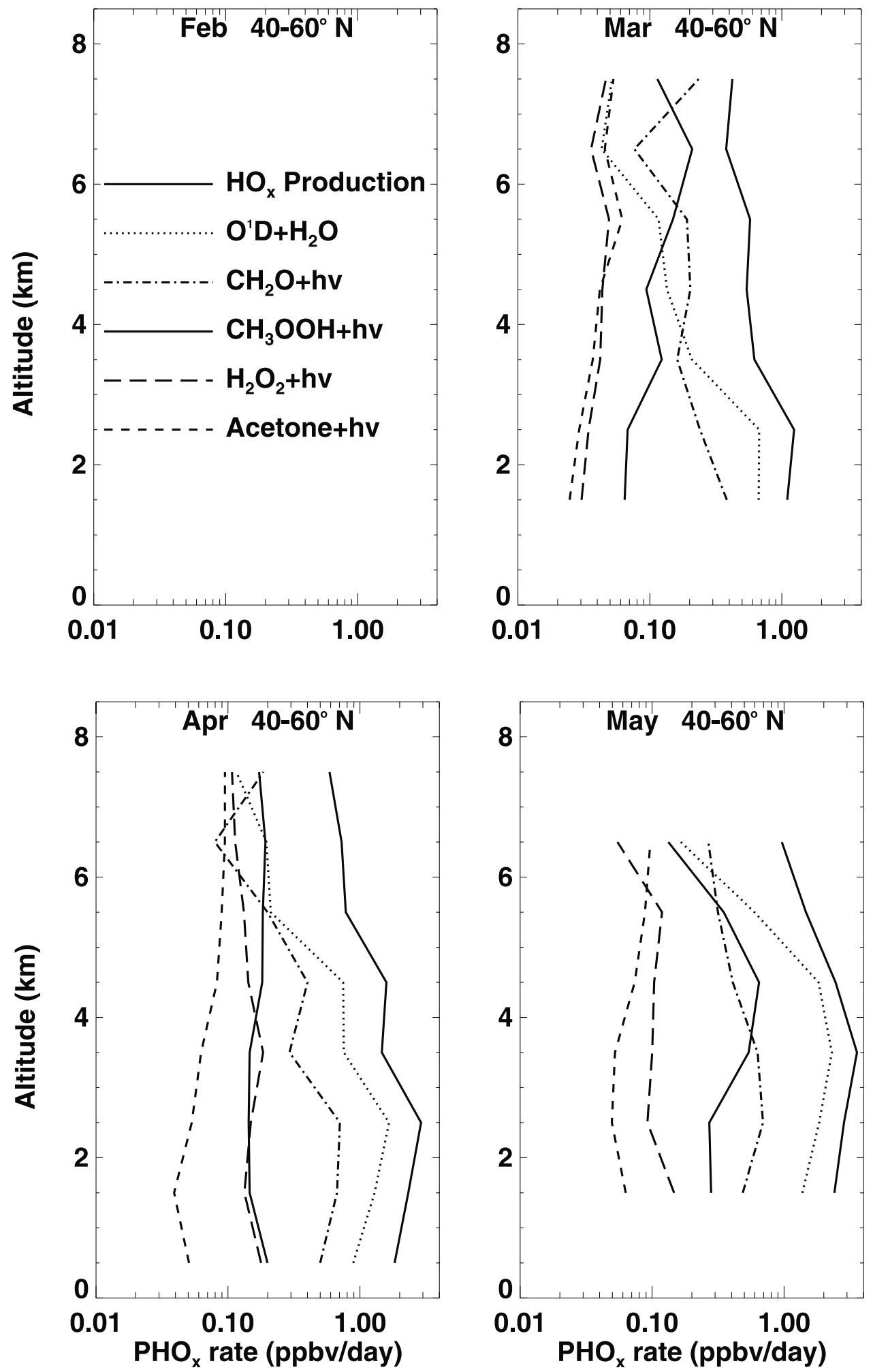

Figure 4. Same as Figure 1 but for simulated 24-hour average $\mathrm{HO}_{x}$ sources. The model is constrained with observed peroxide and $\mathrm{CH}_{2} \mathrm{O}$ concentrations. The $\mathrm{HO}_{x}$ yield of $\mathrm{CH}_{2} \mathrm{O}$ photolysis is computed on line.

from April to May) at high latitudes. Simple rainout that applies both to $\mathrm{HNO}_{3}$ and $\mathrm{H}_{2} \mathrm{O}_{2}$ cannot explain the different characteristics in the required scavenging frequencies of the two species and the rapid rates of $\mathrm{H}_{2} \mathrm{O}_{2}$ removal at mid- latitudes. Similar results for $\mathrm{H}_{2} \mathrm{O}_{2}$ scavenging are obtained when using the rate constant of the $\mathrm{HO}_{2}$ self reaction recommended by Christensen et al. [2002]. One possible pathway is heterogeneous removal of $\mathrm{H}_{2} \mathrm{O}_{2}$ by $\mathrm{SO}_{2}$ oxida- 

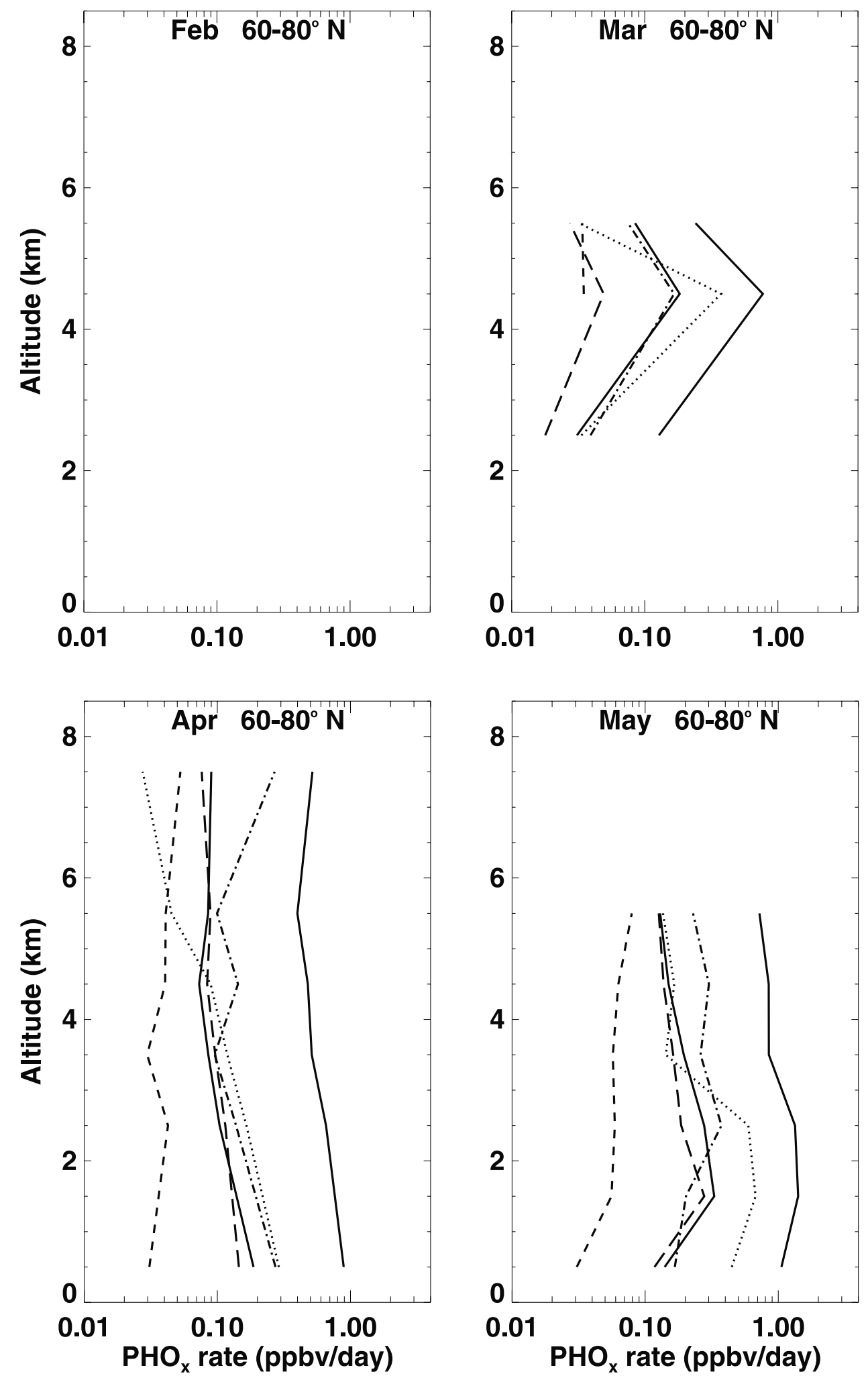

Figure 4. (continued)

tion in droplets [e.g., Hoffmann and Edwards, 1975]. The observed monthly median profiles of $\mathrm{SO}_{2}$ concentrations (not shown) peak in February and are lowest in May. The concentrations are generally in the range of $10-60 \mathrm{pptv}$, which are too low to account for significant $\mathrm{H}_{2} \mathrm{O}_{2}$ loss.
Furthermore, considering that the average photochemical steady state concentrations of $\mathrm{H}_{2} \mathrm{O}_{2}$ are $>1$ ppbv at midlatitudes from March to May and that the required scavenging lifetime is $<1$ day, the supply of $\mathrm{SO}_{2}$ to the TOPSE region needs to be $>1$ ppbv/day. In terms of the sulfur 

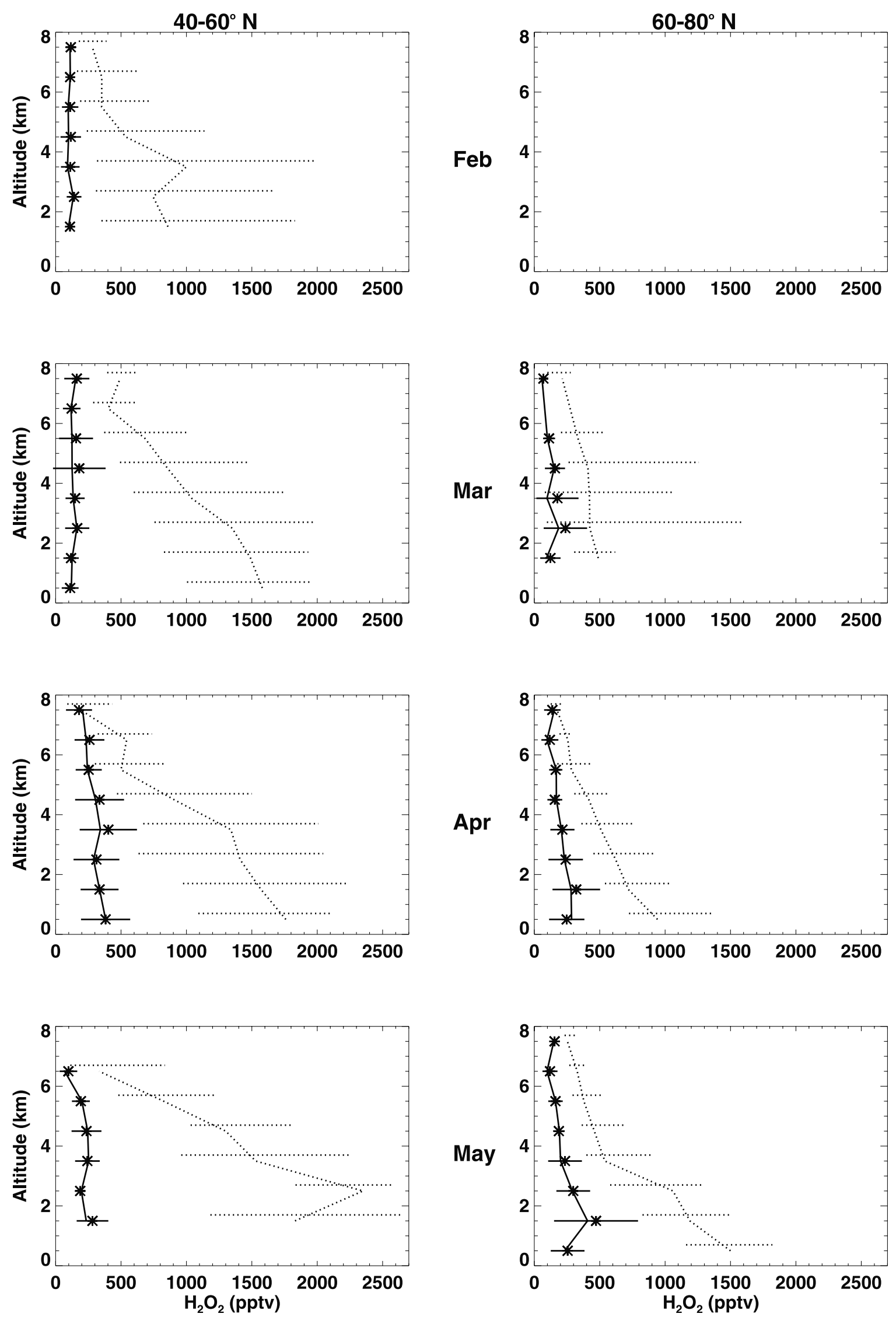

Figure 5. Same as Figure 3 but for $\mathrm{H}_{2} \mathrm{O}_{2}$. The model is not constrained by observed peroxides. 

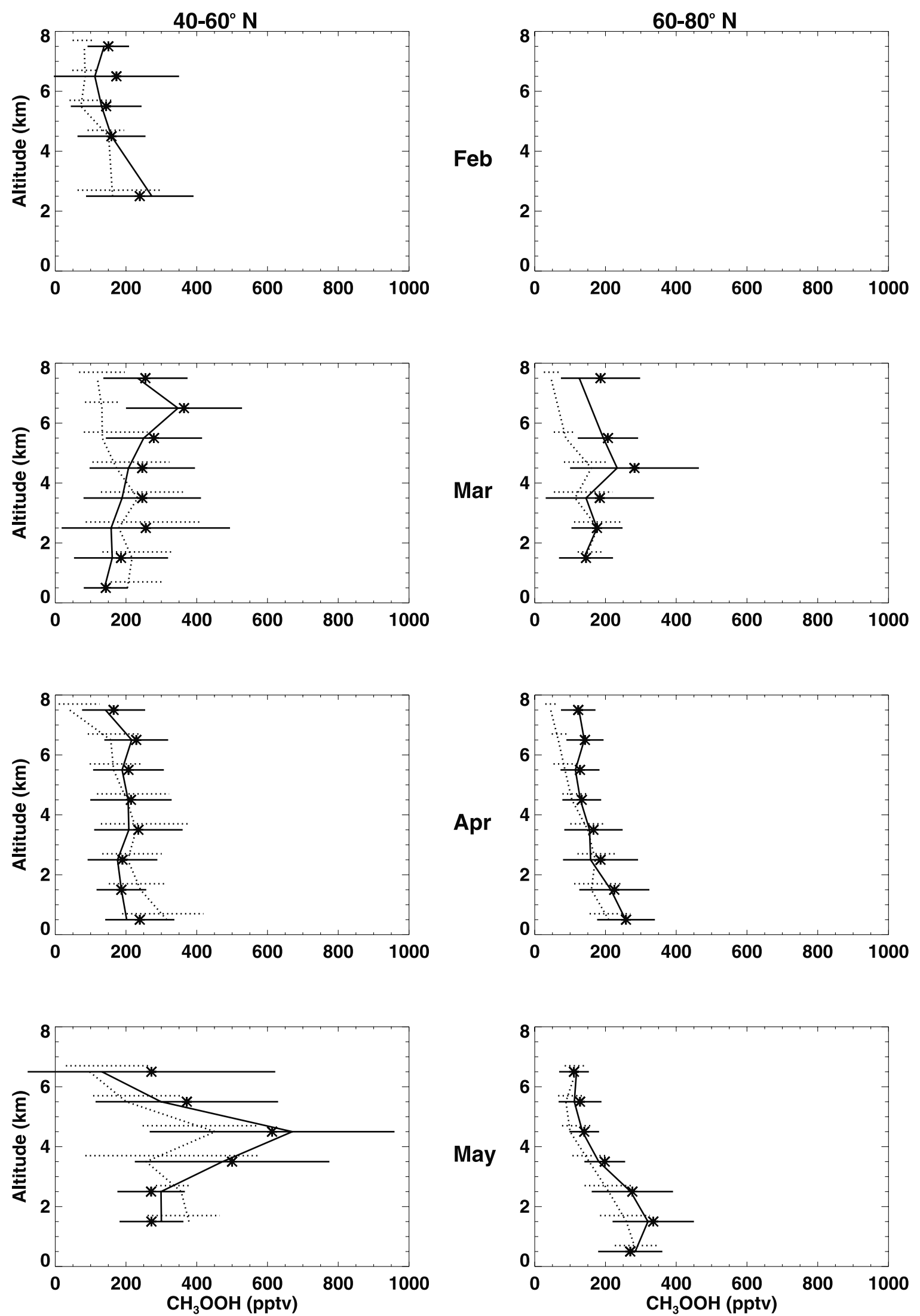

Figure 6. Same as Figure 3 but for $\mathrm{CH}_{3} \mathrm{OOH}$. The model is constrained by observed $\mathrm{H}_{2} \mathrm{O}_{2}$ concentrations. 

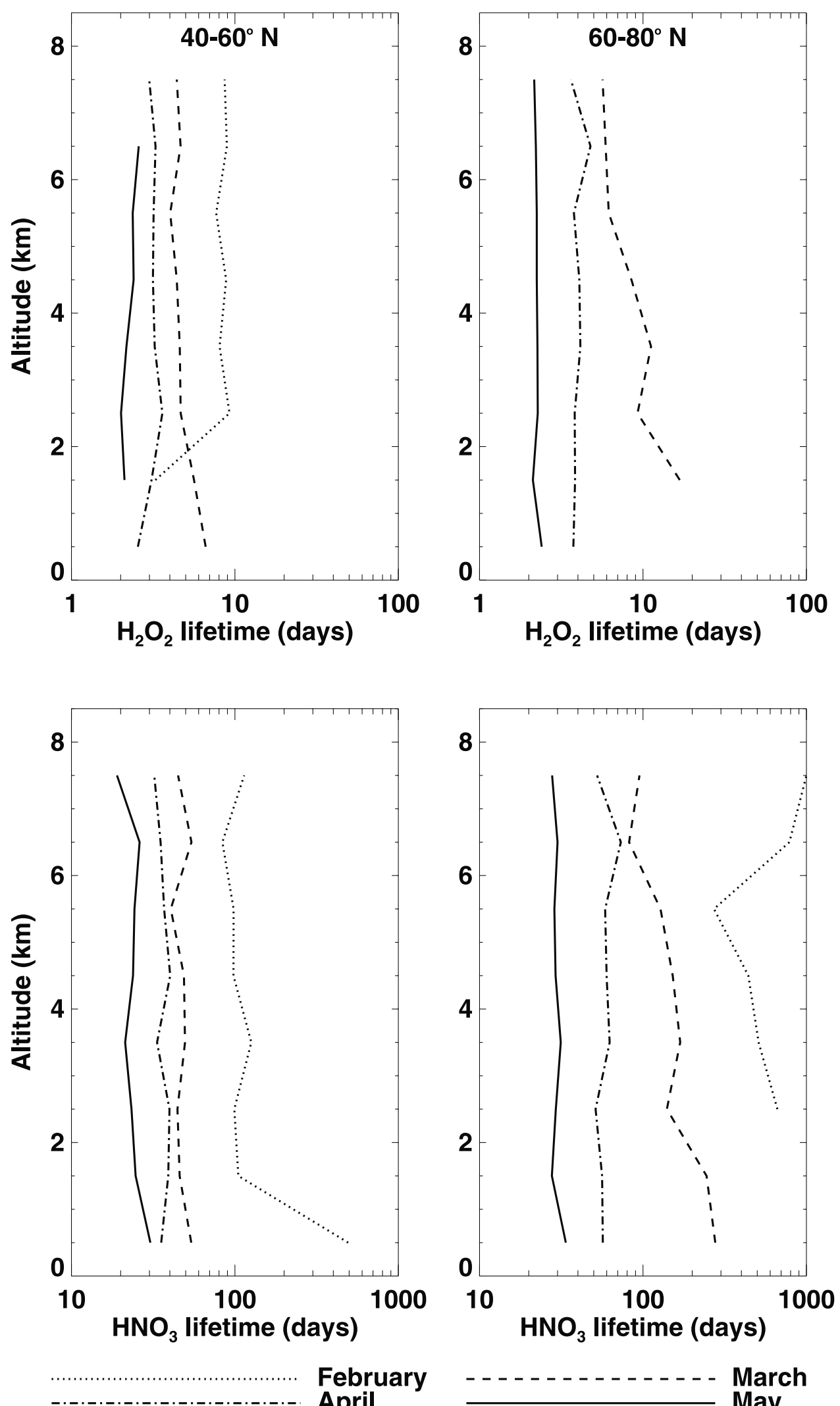

\section{March May}

Figure 7. Same as Figure 1 but for simulated photochemical lifetimes of $\mathrm{H}_{2} \mathrm{O}_{2}$ and $\mathrm{HNO}_{3}$. 

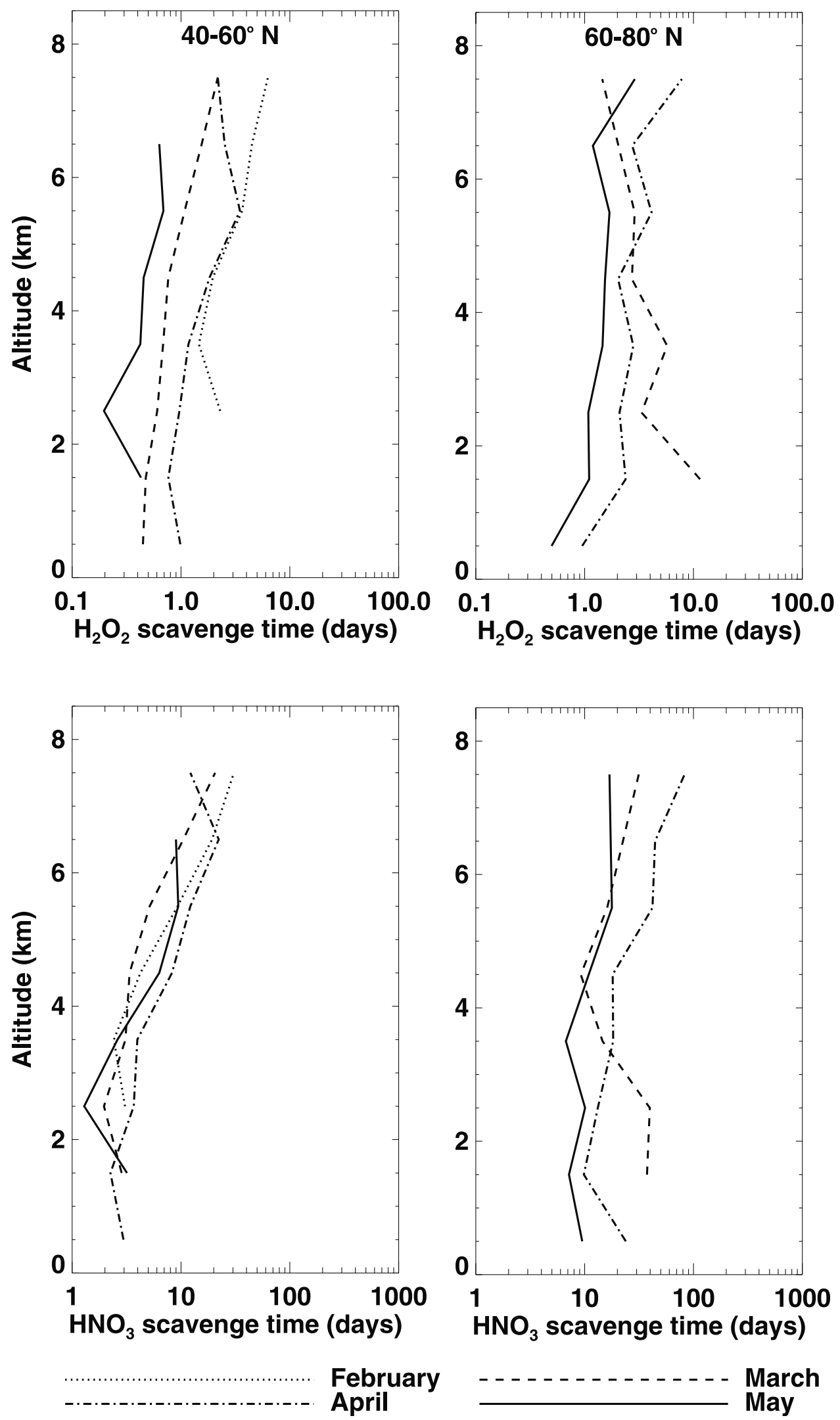

Figure 8. Same as Figure 1 but for estimated scavenging timescales of $\mathrm{H}_{2} \mathrm{O}_{2}$ and $\mathrm{HNO}_{3}$ necessary to explain the observed concentrations. 
budget, it implies a $\mathrm{SO}_{4}^{2-}$ wet deposition rate for the TOPSE region of $>2.5 \mathrm{~g} \mathrm{~S} \mathrm{~m}^{-2} \mathrm{yr}^{-1}$, a rate more than 1 order of magnitude larger than estimated by Langer and Rodhe [1991]. Other $\mathrm{SO}_{2}$ like compounds are necessary to explain the derived scavenging rates.

[21] A survey of previous comparisons of simulated and observed $\mathrm{H}_{2} \mathrm{O}_{2}$ concentrations suggests that the rapid scavenging loss required for TOPSE observations is unique. The box models used in the analyses cited below are similar to the one used in this study and $\mathrm{H}_{2} \mathrm{O}_{2}$ was measured in a similar manner in those field experiments as during TOPSE. Davis et al. [1996] showed relatively good agreement between simulated and observed $\mathrm{H}_{2} \mathrm{O}_{2}$ during PEM-West A over the western Pacific (September-October). Heterogeneous removal of $\mathrm{H}_{2} \mathrm{O}_{2}$ was assumed in that model to have a timescale of 5 days below $4 \mathrm{~km}$ and longer at higher altitude. Jacob et al. [1996] found that the model could account for most of the observed $\mathrm{H}_{2} \mathrm{O}_{2}$ at $0-8 \mathrm{~km}$ during TRACE-A over the tropical South Atlantic (SeptemberOctober). Schultz et al. [1999] found good simulationmeasurement agreement at $2-8 \mathrm{~km}$ but the model was too high by a factor of 2 at $0-2 \mathrm{~km}$ during PEM-tropics A over the tropical Pacific (August-September). Jaeglé et al. [2000] showed reasonable agreement between simulated and observed $\mathrm{H}_{2} \mathrm{O}_{2}$ during SONEX over the North Atlantic (October-November). Unlike in the work by Davis et al. [1996], no heterogeneous loss of $\mathrm{H}_{2} \mathrm{O}_{2}$ was included in the other three works. The latter two studies included heterogeneous production of $\mathrm{H}_{2} \mathrm{O}_{2}$ from $\mathrm{HO}_{2}$ on aerosols. The rate of heterogeneous production used by Schultz et al. [1999] is $\mathrm{H}_{2} \mathrm{O}$ dependent with a $\gamma$ of 0.1 whereas that by Jaeglé et al. [2000] depended only on $\mathrm{HO}_{2}$ and aerosol surface area with a $\gamma$ of 0.2 . Without the heterogeneous production, model results would be considerably lower than observations in the work by Jaeglé et al. [2000]. It is unclear what effects heterogeneous production had in the work by Schultz et al. [1999], particularly how much it contributed to the model overestimates at $0-2 \mathrm{~km}$. Wang et al. [2000] showed that a 1-D model with a column convective turnover timescale of 20 days could largely reproduce the observed profile of $\mathrm{H}_{2} \mathrm{O}_{2}$ during PEM-Tropics A.

[22] The required scavenging loss of $\mathrm{H}_{2} \mathrm{O}_{2}$ implies rapid removal of a large reservoir of $\mathrm{HO}_{x}$ and consequently slows down the $\mathrm{HO}_{x}$ cycles and $\mathrm{O}_{3}$ production. Figure 9 shows the ratios of 24-hour average $\mathrm{HO}_{x}$ production, $\mathrm{OH}$ concentrations, and $\mathrm{O}_{3}$ production in the simulations using observed versus simulated $\mathrm{H}_{2} \mathrm{O}_{2}$ concentrations. The relative effects are similar at mid and high latitudes and among different months. The decrease of $\mathrm{HO}_{x}$ source from the photolysis of $\mathrm{H}_{2} \mathrm{O}_{2}$ leads to a loss of $20-40 \%$ in the production of $\mathrm{HO}_{x}$. The decrease of $20-30 \%$ in $\mathrm{OH}$ concentrations is larger than that of $10-20 \%$ for the peroxy radicals (not shown), which results in a similar decrease in $\mathrm{O}_{3}$ production. The photochemical loss (and hence the net production or loss) also decreases in a similar proportion, reflecting the importance of the reaction of $\mathrm{O}_{3}$ and $\mathrm{HO}_{2}$ in $\mathrm{O}_{3}$ loss (section 5).

\section{2. $\mathrm{CH}_{2} \mathrm{O}$ as a Large Source of $\mathrm{HO}_{x}$ at Northern High Latitudes}

[23] Among the $\mathrm{HO}_{x}$ sources shown in Figure 4, the photolysis of $\mathrm{CH}_{2} \mathrm{O}$ is particularly large. Relative to the total $\mathrm{HO}_{x}$ source, it is larger at higher altitudes and latitudes where the decrease of $\mathrm{H}_{2} \mathrm{O}$ vapor concentrations with temperature reduces the source from the reaction of $\mathrm{O}\left({ }^{1} \mathrm{D}\right)$ and $\mathrm{H}_{2} \mathrm{O}$. This $\mathrm{HO}_{x}$ source often reflects the auto-catalytic nature of the $\mathrm{HO}_{x}$ cycles since $\mathrm{CH}_{2} \mathrm{O}$ is largely produced during the $\mathrm{OH}$ oxidation of hydrocarbons.

[24] However, standard gas-phase photochemistry alone cannot explain the observed $\mathrm{CH}_{2} \mathrm{O}$ concentrations at high altitudes in northern high latitudes, where $\mathrm{CH}_{2} \mathrm{O}$ photolysis is of great importance to the $\mathrm{HO}_{x}$ budget. Figure 10 compares model simulated median profiles of $\mathrm{CH}_{2} \mathrm{O}$ with observations. Simulated median $\mathrm{CH}_{2} \mathrm{O}$ concentrations are generally within the standard deviation of the observed concentrations. Whereas good agreement was found for midlatitude observations, simulated $\mathrm{CH}_{2} \mathrm{O}$ concentrations were much lower at high latitudes in March. These underestimates are particularly large at higher altitudes. Fried et al. [2002] further examined the model underestimates and investigated a number of possibilities that could increase $\mathrm{CH}_{2} \mathrm{O}$ production at high latitudes and altitudes, including direct production from the reaction of $\mathrm{CH}_{3} \mathrm{O}_{2}$ and $\mathrm{HO}_{2}$ [Ayers et al., 1997], the decomposition of $\mathrm{CH}_{3} \mathrm{OONO}_{2}$ [Cantrell et al., 2002], and heterogeneous conversion of $\mathrm{CH}_{3} \mathrm{OH}$ to $\mathrm{CH}_{2} \mathrm{O}$ in aerosols [Singh et al., 2000]. They found no clear evidence attributing the observed excess $\mathrm{CH}_{2} \mathrm{O}$ to these pathways. Another hypothesis is mixing between mid and high latitude air masses enhances $\mathrm{CH}_{2} \mathrm{O}$ concentrations at high latitudes.

[25] Simulated $\mathrm{CH}_{2} \mathrm{O}$ concentrations are affected by $\mathrm{CH}_{3} \mathrm{OOH}$ concentrations [Liu et al., 1992]. The sensitivity varies. The model underestimates at high altitudes are larger when model simulated $\mathrm{CH}_{3} \mathrm{OOH}$ concentrations are used instead of observed $\mathrm{CH}_{3} \mathrm{OOH}$ (Figure 11). The effect is particularly large at $6-8 \mathrm{~km}$ in March; using observed in place of simulated $\mathrm{CH}_{3} \mathrm{OOH}$ concentrations in the model increases $\mathrm{CH}_{2} \mathrm{O}$ concentrations by about $50-$ $100 \%(20-30 \mathrm{pptv})$. In general, the enhancements are above $4 \mathrm{~km}$; the increase is about $10-40 \%$ in April and May. The assumption used to calculate acetone concentrations by scaling to $\mathrm{CO}$ concentrations is another factor contributing to the uncertainty in the simulated $\mathrm{CH}_{2} \mathrm{O}$ concentrations. Jacob et al. [2002] suggested that acetone concentrations are lower in winter and spring than in the fall due to the loss of acetone to the oceans. Reducing our estimated acetone concentrations by half matches the levels (300-600 ppbv) simulated by Jacob et al. [2002] for North America in January. The lowering of acetone concentrations decreases simulated $\mathrm{CH}_{2} \mathrm{O}$ concentrations by $10-20 \%$ above $5 \mathrm{~km}$, which will increase the underestimates by the model.

[26] It is unclear if the additional $\mathrm{CH}_{2} \mathrm{O}$ beyond the level that can be sustained by the standard gas-phase photochemistry is a primary or secondary source of $\mathrm{HO}_{x}$ at high altitudes since the nature of the model underestimate is unknown. However, we can examine the various hypotheses more closely. If the additional $\mathrm{CH}_{2} \mathrm{O}$ is due to transport or conversion of $\mathrm{CH}_{3} \mathrm{OH}$ in aerosols, its photolysis increases the primary $\mathrm{HO}_{x}$ source. If it is due to production from the reaction of $\mathrm{CH}_{3} \mathrm{O}_{2}$ and $\mathrm{HO}_{2}$ or from $\mathrm{CH}_{3} \mathrm{OONO}_{2}$ decomposition, the additional $\mathrm{HO}_{x}$ source is secondary. Boosting the secondary $\mathrm{HO}_{x}$ source implies more efficient yields of $\mathrm{CH}_{2} \mathrm{O}$ from hydrocarbon oxidation. Considering that $\mathrm{CH}_{4}$ oxidation provides about $70-80 \%$ of the total $\mathrm{CH}_{2} \mathrm{O}$ source 

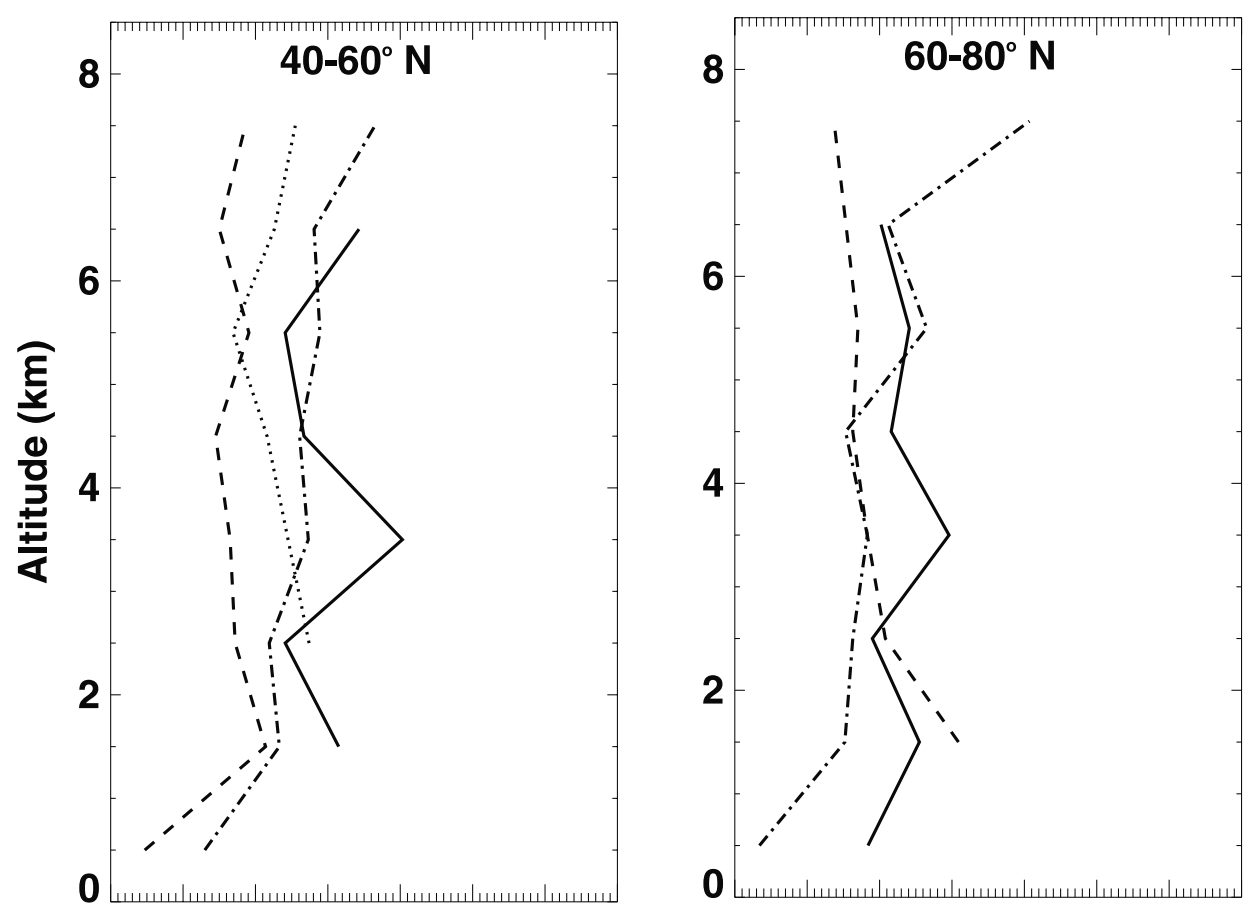

$0.5 \quad 0.60 .70 .80 .91 .01 .11 .2$ $\mathrm{HO}_{\mathrm{x}}$ production ratio
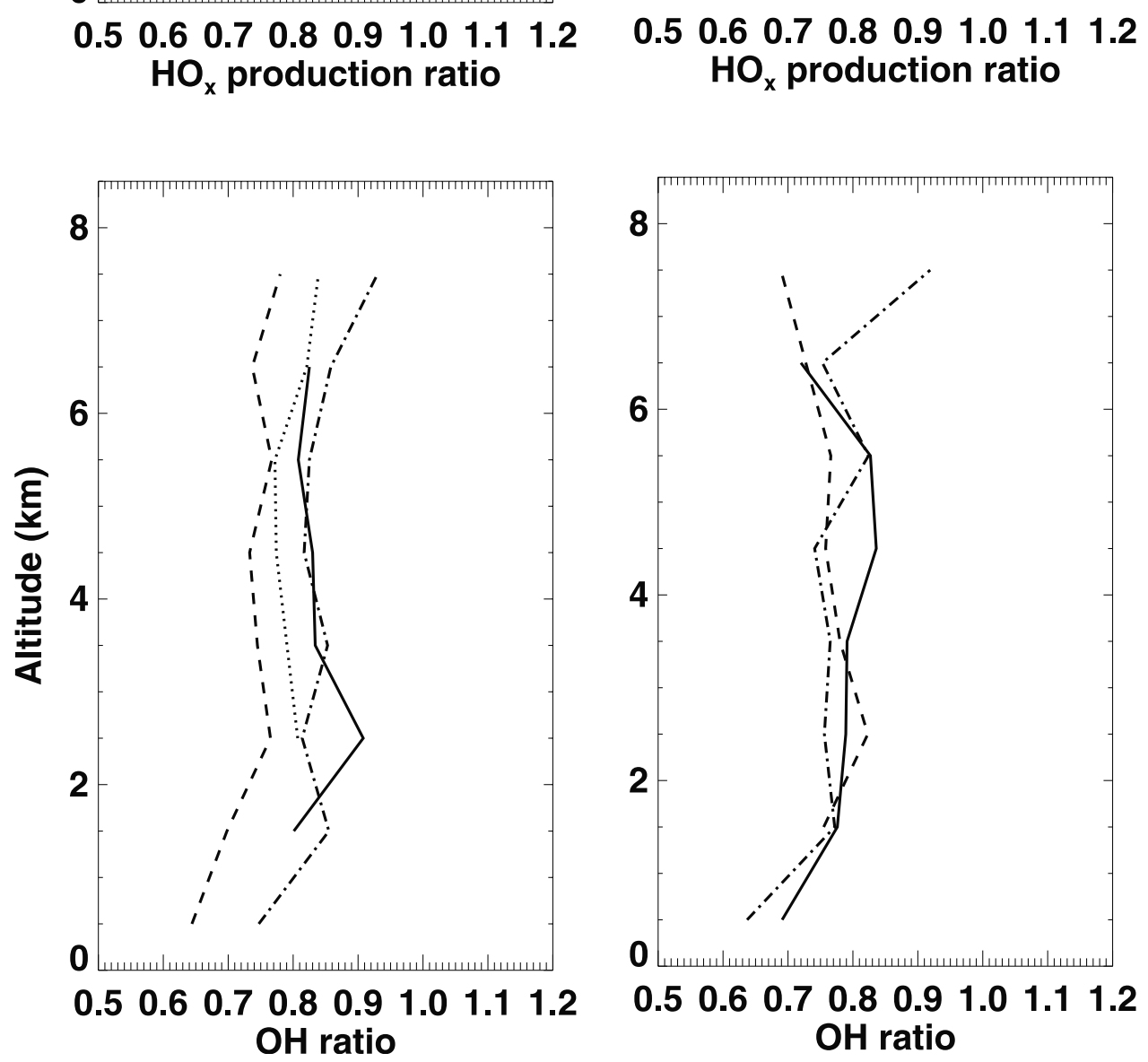

Figure 9. The monthly median ratios of simulated 24-hour average $\mathrm{HO}_{x}$ production, $\mathrm{OH}$ concentrations, and $\mathrm{O}_{3}$ production with relative to without constraining $\mathrm{H}_{2} \mathrm{O}_{2}$ to the observed values in the model. A median value plotted represents a minimum of 10 data points. 


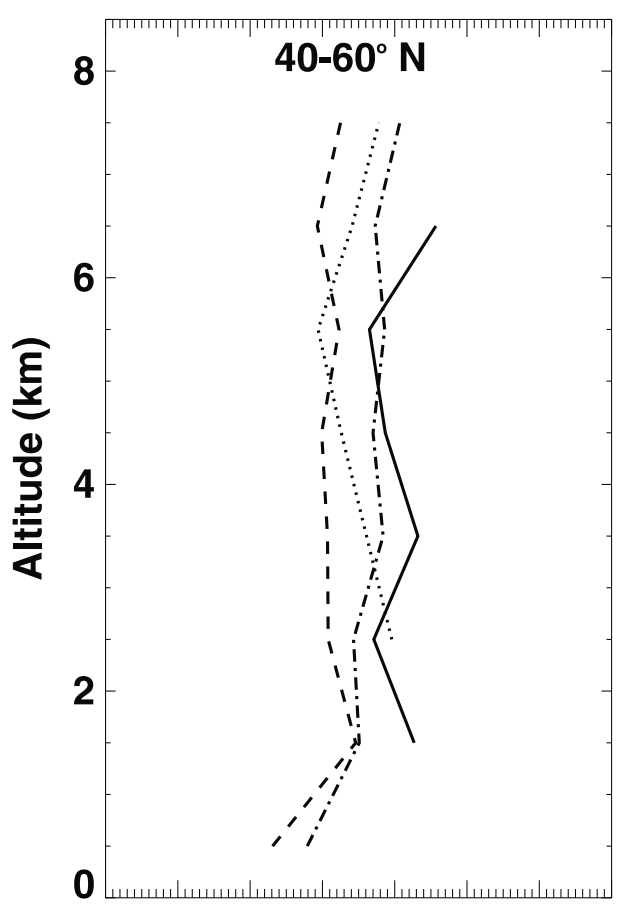

\section{$\begin{array}{llllllll}0.5 & 0.6 & 0.7 & 0.8 & 0.9 & 1.0 & 1.1 & 1.2\end{array}$} $\mathrm{O}_{3}$ production ratio

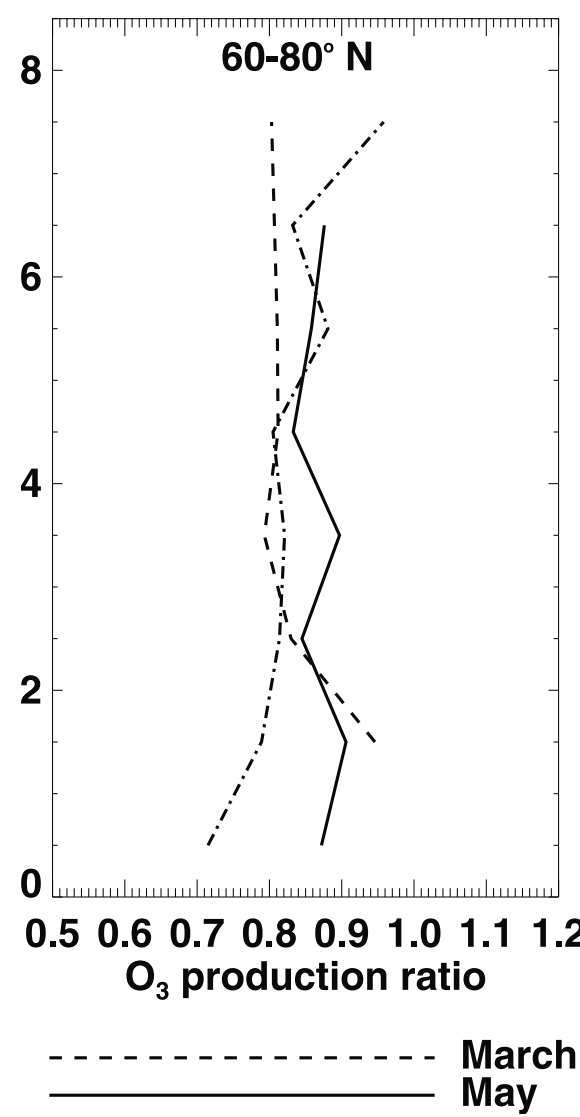

February
April

Figure 9. (continued) and that the yield of $\mathrm{CH}_{2} \mathrm{O}$ from this oxidation is already close to 1 in the box model (with no heterogeneous loss of $\mathrm{CH}_{3} \mathrm{OOH}$ assumed), it is unlikely that these pathways will significantly increase $\mathrm{CH}_{2} \mathrm{O}$ concentrations to make up for the large underestimates shown in Figure 10. Therefore, it is more likely that the additional $\mathrm{HO}_{x}$ source from $\mathrm{CH}_{2} \mathrm{O}$ photolysis is primary.

[27] Figure 12 shows the ratios of 24-hour average $\mathrm{HO}_{x}$ production, $\mathrm{OH}$ concentrations, and $\mathrm{O}_{3}$ production in the simulations using observed versus simulated $\mathrm{CH}_{2} \mathrm{O}$ concentrations. The effects are significant at high latitudes above $6 \mathrm{~km}$ and are larger in March than in May. The largest effect is seen in the total production of $\mathrm{HO}_{x}$, decreasing from a factor of 2 to $30 \%$ from March to May above $6 \mathrm{~km}$ at high latitudes. In the region, the concentrations of $\mathrm{OH}$ and $\mathrm{HO}_{2}$ (not shown) and the production of $\mathrm{O}_{3}$ increase by $20-50 \%$. The seasonal decrease in the relative contribution of the "excess" $\mathrm{CH}_{2} \mathrm{O}$ to $\mathrm{HO}_{x}$ reflects in part the increasing contribution from the reaction $\mathrm{O}\left({ }^{1} \mathrm{D}\right)$ and $\mathrm{H}_{2} \mathrm{O}$ to the $\mathrm{HO}_{x}$ source with time and in part lesser underestimates by the model in late spring [Fried et al., 2002]. The effects are minimal at midlatitudes where simulated and observed $\mathrm{CH}_{2} \mathrm{O}$ concentrations are in better agreement. Photolysis of acetone also affects $\mathrm{HO}_{x}$ chemistry at high altitudes [e.g., McKeen et al., 1997]. During the TOPSE period, it is not the dominant $\mathrm{HO}_{x}$ sources (Figure 4). Reducing acetone concentrations estimated in the model by half decreases $\mathrm{HO}_{x}$ production by up to 12 and $20 \%$ at mid and high latitudes $(>6 \mathrm{~km})$, respectively. The effects on the concentration of $\mathrm{OH}$ and $\mathrm{O}_{3}$ production are around $10 \%$ at altitude above $6 \mathrm{~km}$. The effects are insignificant below $4 \mathrm{~km}$ where the source from the reaction of $\mathrm{O}\left({ }^{1} \mathrm{D}\right)$ and $\mathrm{H}_{2} \mathrm{O}$ dominates $\mathrm{HO}_{x}$ production.

\section{Nitrogen Oxides and In Situ $\mathrm{O}_{3}$ Production}

[28] Figure 13 compares simulated and observed monthly median profiles of $\mathrm{NO}_{2}$ at mid and high latitudes. Although the simulated median profiles of $\mathrm{NO}_{2}$ at given altitude bins are within the observed monthly standard deviations, which are often larger than the scale of the plots and are hence not shown, simulated $\mathrm{NO}_{2}$ concentrations tend to be lower than the observations. The underestimates are largest above $6 \mathrm{~km}$ (about 10 pptv). Some of the discrepancies can be attributed to the measurement uncertainty, which increases with altitude from 3 pptv to 8 pptv. The increasing measurement uncertainties with altitude are also reflected in the increasing proportion of data near the detection limits, reaching $50 \%$ at $6-8 \mathrm{~km}$. The model overestimate at $1-2 \mathrm{~km}$ in February at midlatitudes is due to some high concentration plumes sampled by the $\mathrm{C}-130$. On the basis of observed NO concentrations, the model predicts broader plumes than found in the $\mathrm{NO}_{2}$ measurements. When model points with no corresponding $\mathrm{NO}_{2}$ measurements are included, the median model value drops to $25 \mathrm{pptv}$ and is in agreement with the observations. The seasonal increase of NO concentrations during TOPSE is shown in Figure 1. In comparison, the seasonal increase of $\mathrm{NO}_{2}$ is much smaller, reflecting the shift of $\mathrm{NO}_{x}$ partition toward $\mathrm{NO}$ as photolysis of $\mathrm{NO}_{2}$ increases with time. 

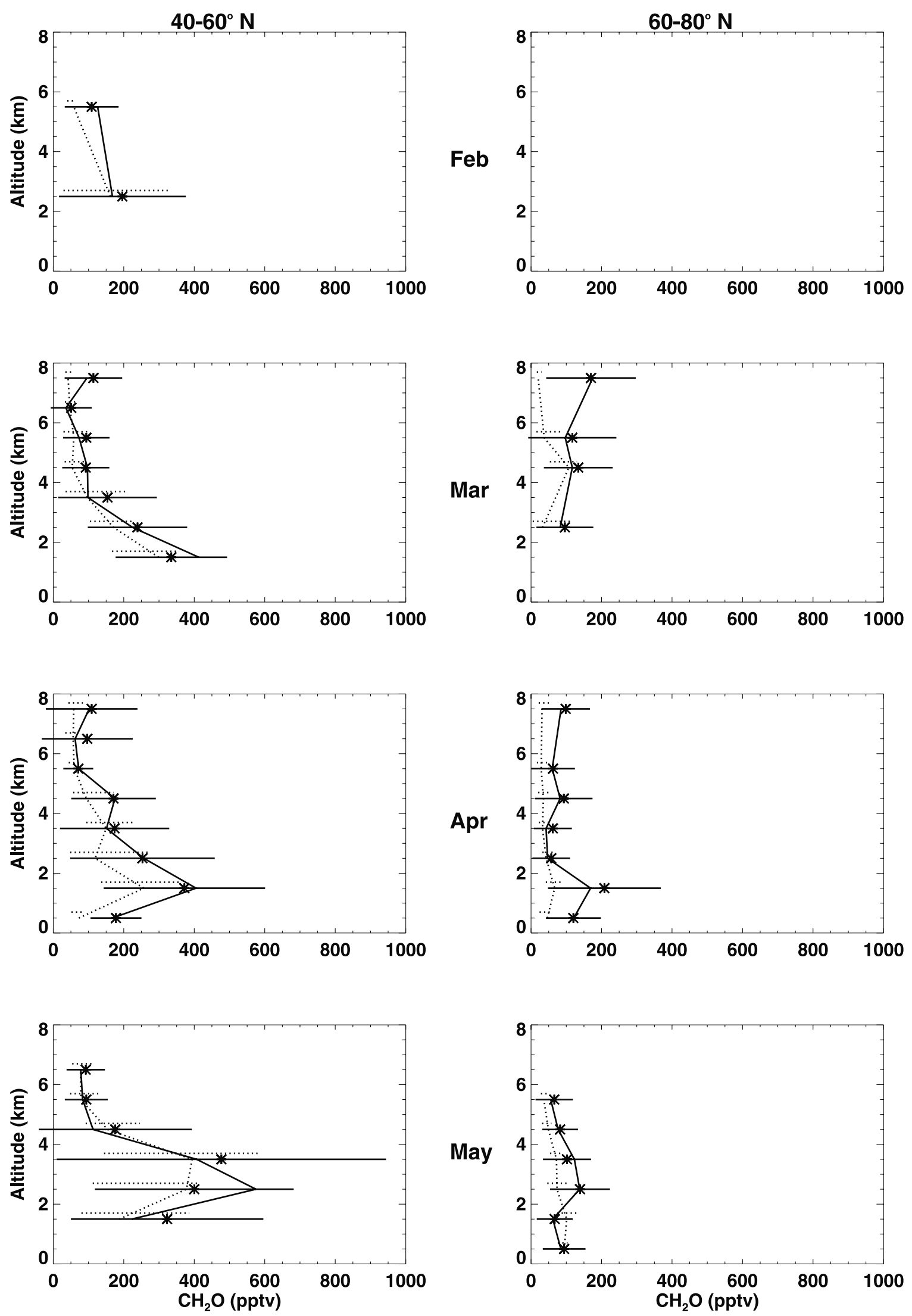

Figure 10. Same as Figure 3 but for $\mathrm{CH}_{2} \mathrm{O}$. A median value plotted represents a minimum of 5 data points. 

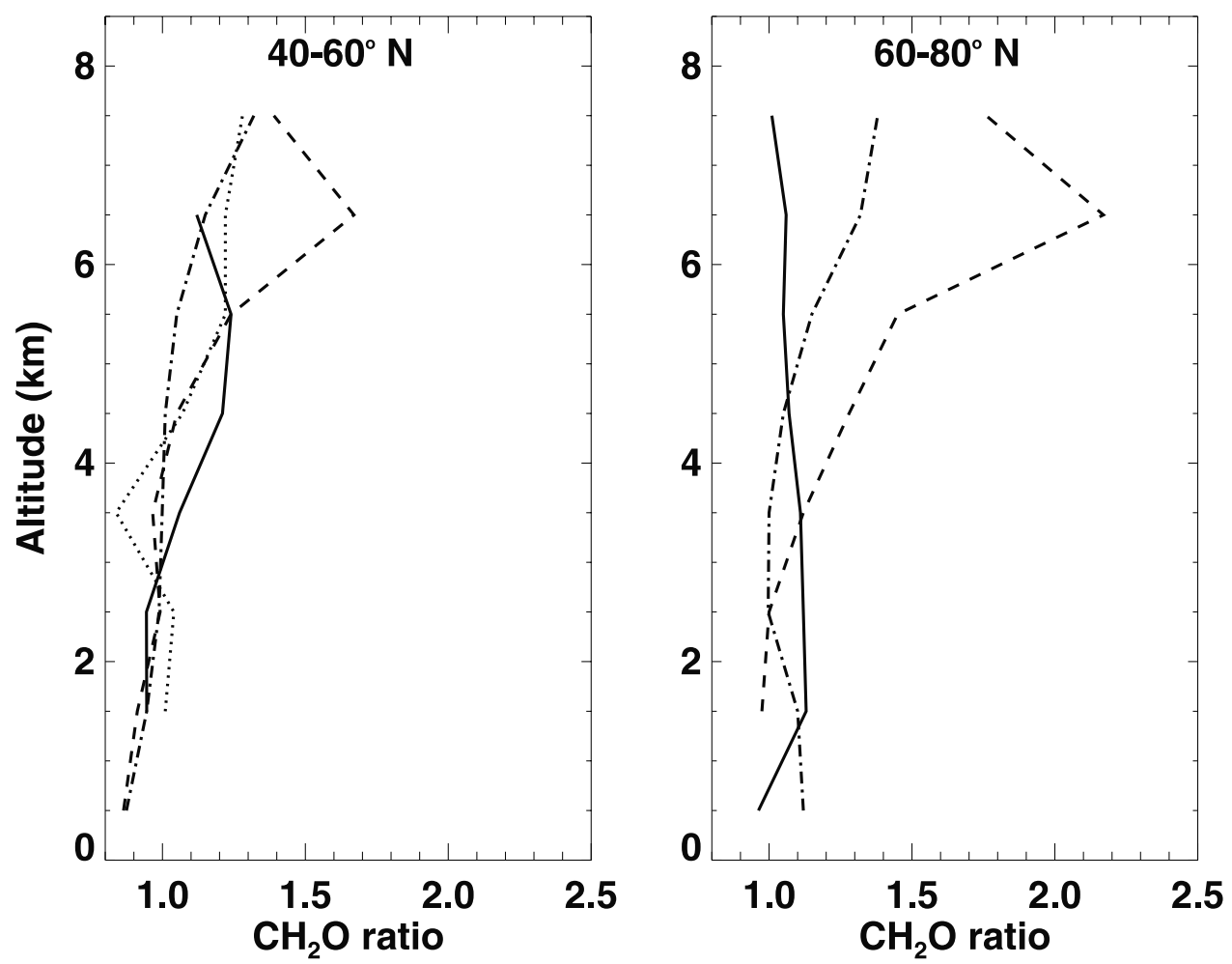

February April

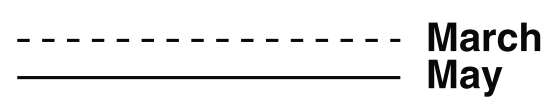

Figure 11. The monthly median ratios of simulated $\mathrm{CH}_{2} \mathrm{O}$ concentrations with relative to without constraining $\mathrm{CH}_{3} \mathrm{OOH}$ to observed values in the model. Each median value represents a minimum of 5 data points. The model is constrained by observed $\mathrm{H}_{2} \mathrm{O}_{2}$ concentrations.

[29] Jaeglé et al. [1999] mapped $\mathrm{O}_{3}$ production as a function of the primary source of $\mathrm{HO}_{x}$ and $\mathrm{NO}_{x}$ concentration for the observations during SONEX. Figure 14 shows the mapping for TOPSE observations, where the primary $\mathrm{HO}_{x}$ source is driven mostly by the reaction of $\mathrm{O}\left({ }^{1} \mathrm{D}\right)$ and $\mathrm{H}_{2} \mathrm{O}$. Compared with SONEX, two features stand out. First, there is a clear positive correlation between primary $\mathrm{HO}_{x}$ production and $\mathrm{NO}_{x}$ concentrations, whereas Jaeglé et al. [1999] found marine convected air masses (over the North Atlantic) with high primary $\mathrm{HO}_{x}$ production but low $\mathrm{NO}_{x}$ concentrations during SONEX. During TOPSE, the positive correlation reflects the convergence of favorable photochemical environment (Figure 4) and increasing $\mathrm{NO}_{x}$ concentrations. Second, in the same range of primary $\mathrm{HO}_{x}$ production rates and $\mathrm{NO}_{x}$ concentrations, the $\mathrm{O}_{3}$ production rates are similar between TOPSE and SONEX despite that our work is for $0-8 \mathrm{~km}$ in spring and the work by Jaegle et al. [1999] is for $8-12 \mathrm{~km}$ in the fall.

[30] A casual look of the first panel of Figure 14 would suggest that the primary $\mathrm{HO}_{x}$ production does not play a significant role in the production rate of $\mathrm{O}_{3}$. Part of the insensitivity of $\mathrm{O}_{3}$ production to the primary $\mathrm{HO}_{x}$ source is due to the rapid increase of $\mathrm{NO} / \mathrm{NO}_{2}$ ratio with altitude, which is driven by the temperature dependence of the $\mathrm{NO}+$ $\mathrm{O}_{3}$ reaction and the altitude dependence of air density and photon flux. The same amount of $\mathrm{NO}_{x}$ is therefore more effective in $\mathrm{O}_{3}$ production at high altitudes where $\mathrm{NO} / \mathrm{NO}_{2}$ ratio is high since the production is driven by the reaction of
NO with peroxy radicals. This effect combined with a decreasing trend of the $\mathrm{HO}_{x}$ primary production with altitude tends to mask the contribution of the primary $\mathrm{HO}_{x}$ source to $\mathrm{O}_{3}$ production.

[31] We therefore mapped $\mathrm{O}_{3}$ production as a function of NO in Figure 14 as well. At NO levels above 10 pptv, it is clear that increasing the primary $\mathrm{HO}_{x}$ source enhances $\mathrm{O}_{3}$ production. Considering that the range of the primary $\mathrm{HO}_{x}$ source spans about 4 orders of magnitudes, the efficiency of primary $\mathrm{HO}_{x}$ production in boosting $\mathrm{O}_{3}$ production $\left(\partial \mathrm{P}\left(\mathrm{O}_{3}\right) /\right.$ $\left.\partial \mathrm{P}\left(\mathrm{HO}_{x}\right)\right)$ is less than that of $\mathrm{NO}_{x}$ (or $\mathrm{NO}$ ). However, it should be noted that the increase of primary $\mathrm{HO}_{x}$ production through the spring is much more rapid than that of $\mathrm{NO}$ (Figures 1 and 4). The large dependence of $\mathrm{O}_{3}$ production on $\mathrm{NO}$ concentrations reflects a $\mathrm{NO}_{x}$-limited photochemical regime during TOPSE.

\section{Budgets of Reactive Nitrogen and $\mathrm{O}_{3}$}

[32] Penkett and Brice [1986] used the rapid buildup and loss of peroxyacetylnitrate (PAN) at a rural site in spring as a proxy to suggest that intensifying photochemistry activity contributes to the observed springtime $\mathrm{O}_{3}$ maximum. Honrath et al. [1996] further suggested that the accumulation of reactive nitrogen at winter high latitudes and the subsequent decomposition of these reservoirs back to $\mathrm{NO}_{x}$ in spring could contribute to the observed springtime maximum. 

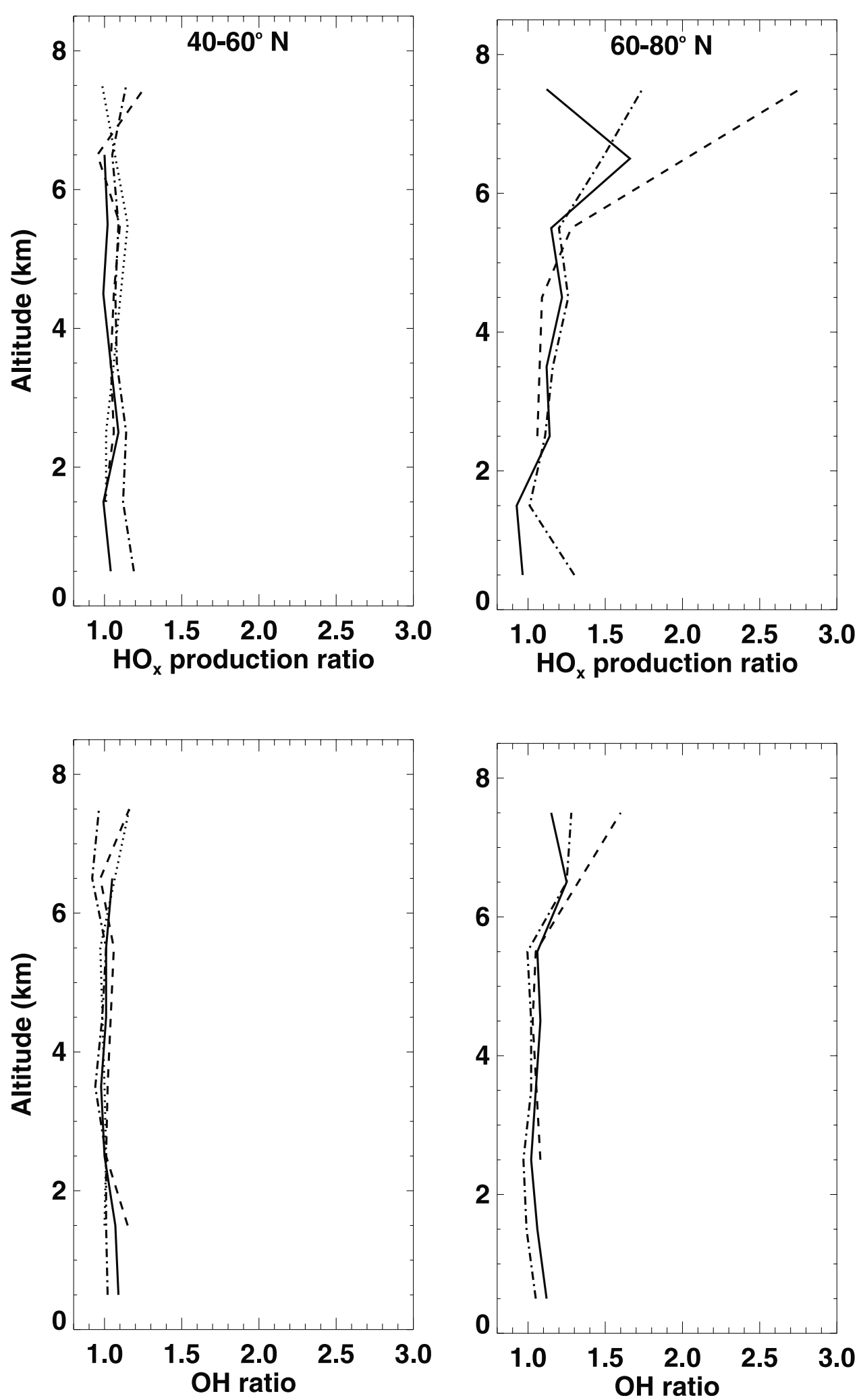

Figure 12. The monthly median ratios of simulated 24-hour average $\mathrm{HO}_{x}$ production, $\mathrm{OH}$, and $\mathrm{O}_{3}$ production with relative to without constraining $\mathrm{CH}_{2} \mathrm{O}$ to the observed values in the model. Peroxides in the model are specified as observed. Each median value represents a minimum of 5 data points.

[33] Figure 15 shows the monthly median profiles of total reactive nitrogen $\left(\mathrm{NO}_{y}\right)$ and PAN concentrations at mid and high latitudes. The most abundant $\mathrm{NO}_{y}$ component is PAN accounting for $40-80 \%$ of $\mathrm{NO}_{y}$. The PAN fraction in $\mathrm{NO}_{y}$ decreases with season. The continually increasing concentrations of $\mathrm{NO}_{y}$ and PAN in the most part of the troposphere show no evidence for wintertime accumulation at high latitudes followed by springtime transport to midlatitudes. 


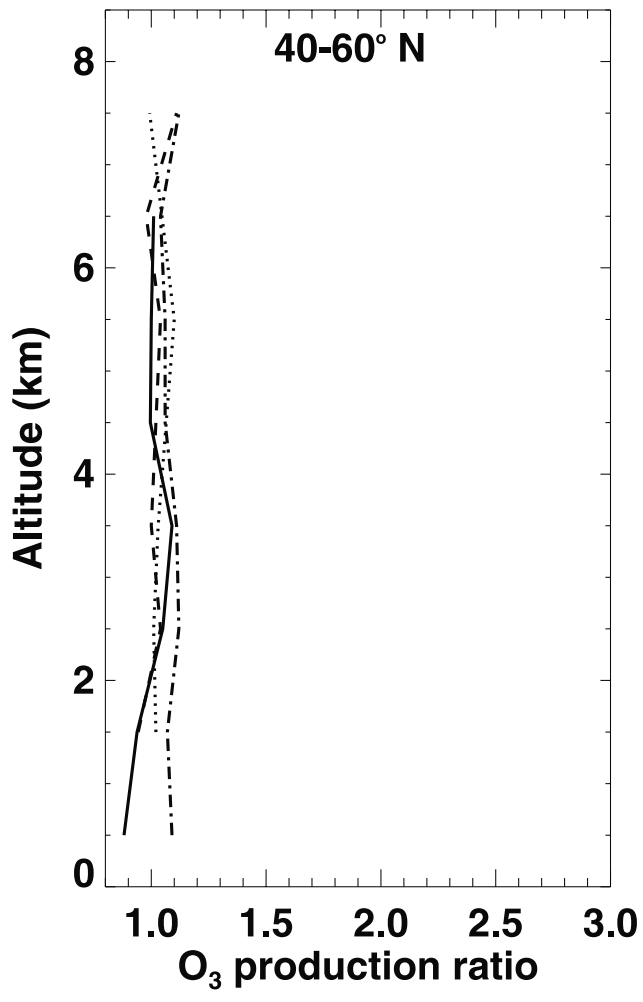

February April
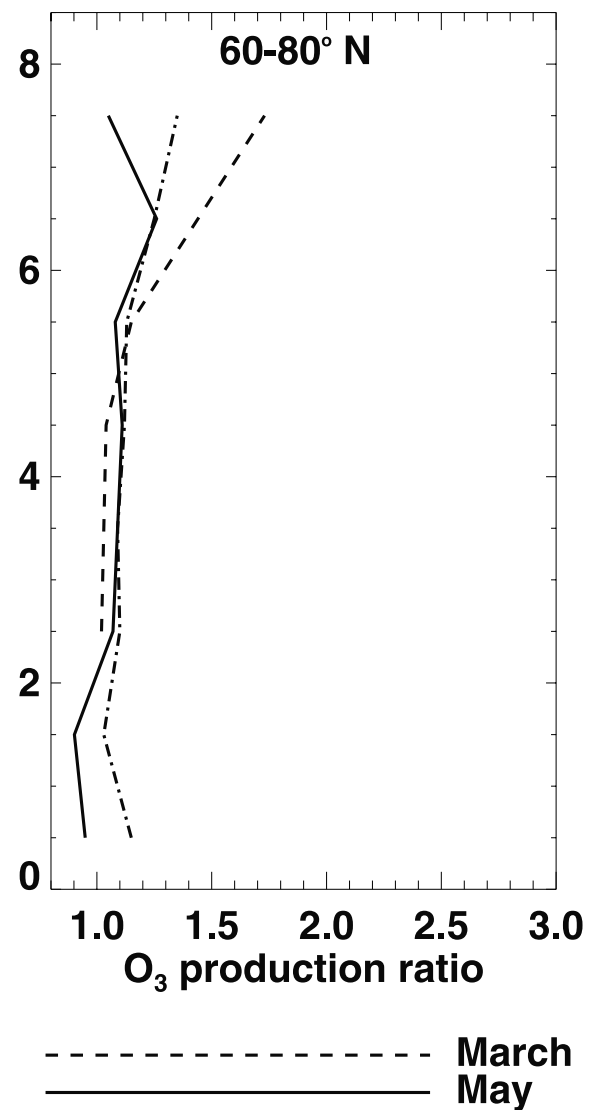

Figure 12. (continued)

Free tropospheric measurements are particularly important in understanding the seasonality of reactive nitrogen species at mid and high latitudes because the seasonal trends are quite different near the surface from that in the free troposphere. Concentrations of $\mathrm{NO}_{y}$ and PAN above $3 \mathrm{~km}$ continue to increase throughout the spring. The seasonal trend at lower altitudes is not as well defined as that at higher altitudes. The concentrations of $\mathrm{NO}_{y}$ tend to peak in February near the surface; the seasonal maximum of PAN near the surface is shifted toward April particularly at midlatitudes.

[34] The apparent disparity in the observed seasonal variations of $\mathrm{NO}_{y}$ and PAN near the surface would imply that some major component of $\mathrm{NO}_{y}$ decreases throughout the spring as NMHCs (Figure 1), particularly in light of the increasing $\mathrm{HNO}_{3}$ concentrations with season (not shown). However, no such component is found. To illustrate the point, we show in Figure 15 the seasonal profiles of $\mathrm{DNO}_{y}$, defined as $\mathrm{NO}_{y}-\left(\mathrm{NO}+\mathrm{NO}_{2}+\mathrm{PAN}+\mathrm{PPN}+\mathrm{HNO}_{3}+\right.$ $2 \mathrm{~N}_{2} \mathrm{O}_{5}+\mathrm{HNO}_{4}$ ). Simulated $\mathrm{N}_{2} \mathrm{O}_{5}$ and $\mathrm{HNO}_{4}$ are used because these species were not measured. We also used model computed $\mathrm{NO}_{2}$ concentrations to increase the availability of data points. Unlike in many tropospheric missions [e.g., Bradshaw et al., 2000], there is generally no need to invoke missing nitrogen species to account for measured $\mathrm{NO}_{y}$ concentrations during TOPSE. The exception is in February when $\mathrm{NO}_{y}$ concentrations are higher than the sums of individual components by $50-100$ pptv. We note the extreme scarcity of overlapping reactive nitrogen data in February; the median profiles for that month are generated from 1-3 points at $1-\mathrm{km}$ intervals. There is an opposite problem most of the time, i.e., measured $\mathrm{NO}_{y}$ concentrations are not enough to match the sums of reactive nitrogen species. This shortfall from $\mathrm{NO}_{y}$ measurements increases from March to May at both mid and high latitudes. Without counting model simulated $\mathrm{HNO}_{4}$ concentrations, the shortfall can be largely eliminated at high altitudes but not at lower altitudes, where simulated $\mathrm{HNO}_{4}$ concentrations are low due to relatively high temperatures. We note that $\mathrm{DNO}_{y}$ carries the uncertainties in the measurements or model simulations of all the components. Detailed analysis of measurement uncertainties is carried out by F. Flocke et al. (The behavior of PAN and the balance of odd nitrogen during TOPSE, submitted to Journal of Geophysical Research, 2002). In particular, there is evidence for occasional interference of particulate and cloud nitrates in the $\mathrm{HNO}_{3}$ measurements (Flocke et al., submitted manuscript, 2002).

[35] We examine now the budget of reactive nitrogen during the TOPSE experiment. Among the reactive nitrogen reservoirs, PAN and $\mathrm{HNO}_{3}$ concentrations are largest. Peroxypropionylnitrate is not simulated in the model. Its behavior follows closely that of PAN (Flocke et al., submitted manuscript, 2002); we hence expect its budget resembles that of PAN as well. Figure 16 shows the seasonal evolution of the net production rates for these two species at mid and high latitudes. Loss of $\mathrm{NO}_{x}$ to $\mathrm{HNO}_{3}$ is likely underestimated particularly at midlatitudes because heterogeneous conversion in aerosols via $\mathrm{N}_{2} \mathrm{O}_{5}$ hydrolysis is not accounted for in the model. There is a net loss of $\mathrm{NO}_{x}$ to $\mathrm{HNO}_{3}$ and PAN during TOPSE. The loss to $\mathrm{HNO}_{3}$ is much more significant at mid than high latitudes because of 

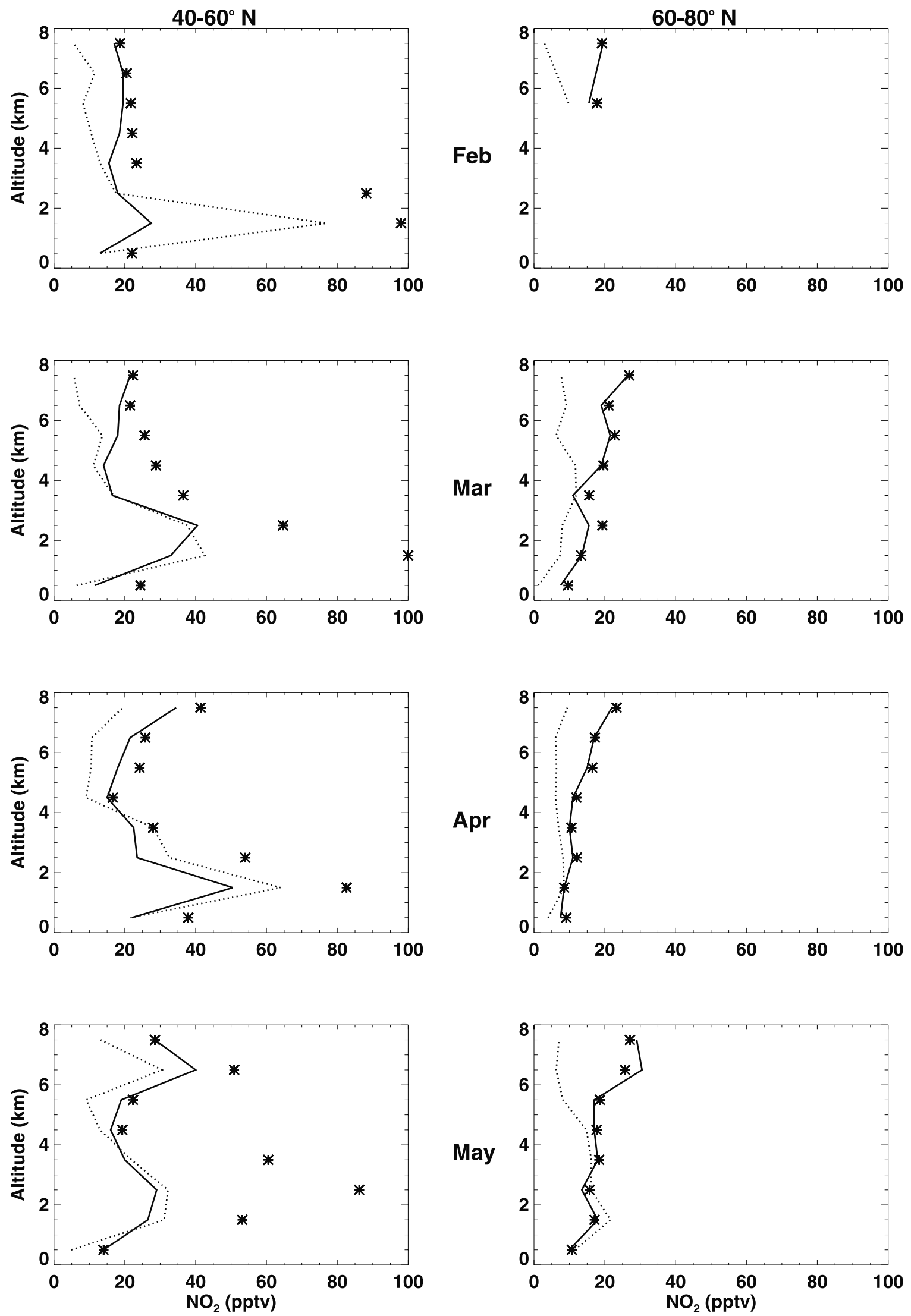

Figure 13. Same as Figure 5 but for $\mathrm{NO}_{2}$. Line symbols are the same as Figure 3. Standard deviations are not shown because of the large data variability, which is reflected in the large differences between observed means and medians at mid latitudes. 

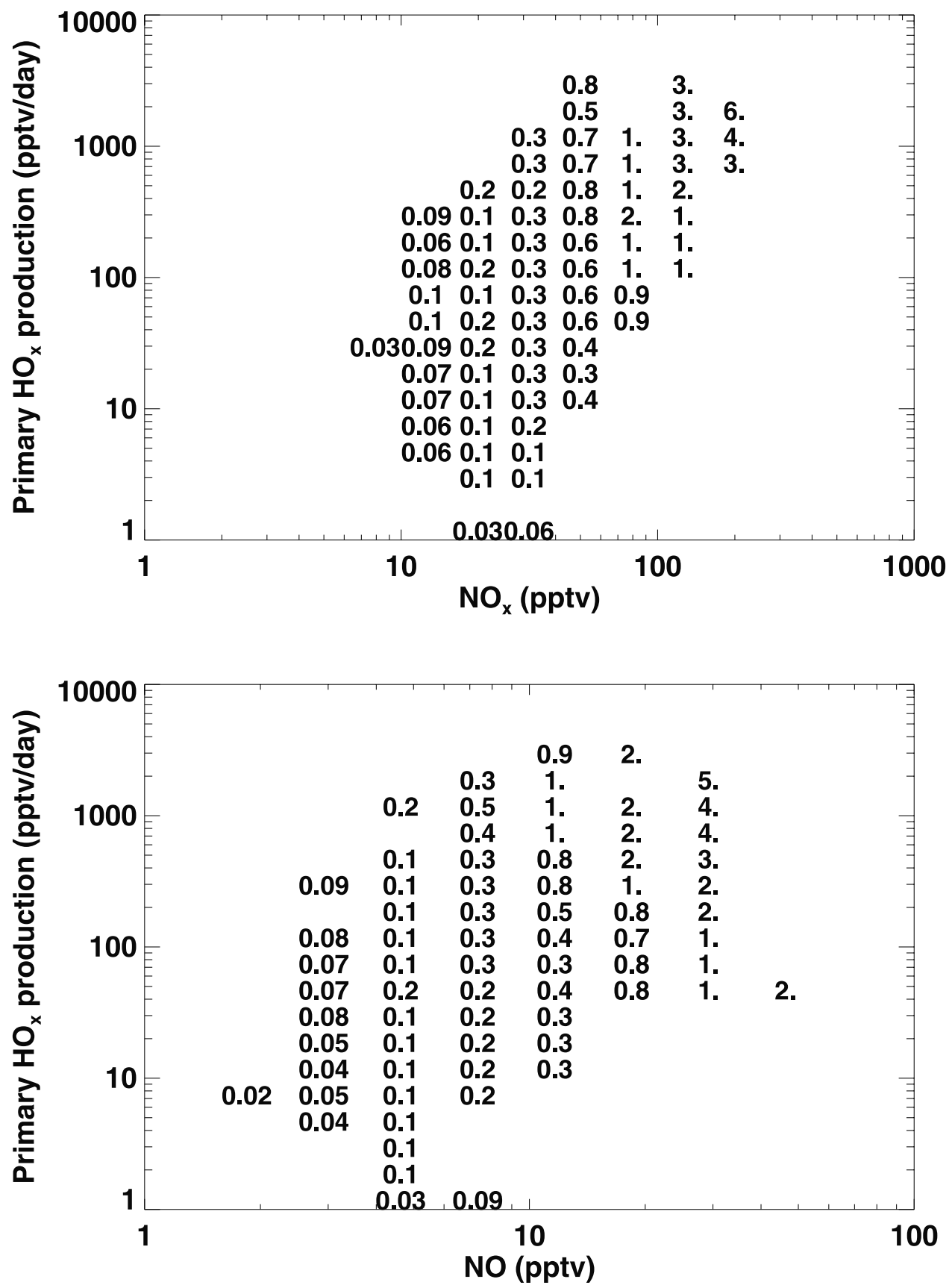

Figure 14. Numerical values of simulated 24-hour average $\mathrm{O}_{3}$ production rates (ppbv/day) as a function of 24-hour average primary $\mathrm{HO}_{x}$ production and $\mathrm{NO}_{x}$ or $\mathrm{NO}$ concentrations. The primary $\mathrm{HO}_{x}$ production is from the reaction of $\mathrm{O}\left({ }^{1} \mathrm{D}\right)$ and $\mathrm{H}_{2} \mathrm{O}$ and photolysis of acetone. Constraining the model with observed peroxide and $\mathrm{CH}_{2} \mathrm{O}$ concentrations would yield similar results but with much fewer data.

higher $\mathrm{OH}$ concentrations at midlatitudes. The net loss of $\mathrm{NO}_{x}$ to PAN is also more significant at about $2 \mathrm{pptv} /$ day at midlatitudes than a rate of about 1 pptv/day at high latitudes. The loss is larger at higher altitudes because of the strong temperature dependence of PAN thermal decomposition. Unlike in the tropics where PAN decomposition provides the main $\mathrm{NO}_{x}$ source in the lower troposphere [Schultz et al., 1999; Wang et al., 2001], PAN formation constitutes a net loss of $\mathrm{NO}_{x}$ at all altitudes during TOPSE. Reducing acetone concentrations in the model by $50 \%$ decreases the net loss of $\mathrm{NO}_{x}$ to PAN by $0.1-1 \mathrm{pptv} /$ day at midlatitudes and $<0.5 \mathrm{pptv} /$ day at high latitudes. It appears clear that the decomposition of long-lived nitrogen reservoirs cannot explain the observed seasonal increase of $\mathrm{NO}_{x}$ during TOPSE. Carpenter et al. [2000] also found that PAN decomposition did not contribute to $\mathrm{NO}_{x}$ concentrations at the Jungfraujoch Observatory $(3.6 \mathrm{~km}$ above sea level) in the Swiss Alps during FREETEX'98. These results are consistent with the finding by Wang et al. [1998] in a global 3-D model study that PAN formation and decomposition generally does not contribute significantly to the observed springtime $\mathrm{O}_{3}$ maxima over northern mid and high latitude continents. More measurements are necessary to understand if and how the $\mathrm{NO}_{x}$ source from PAN decom- 

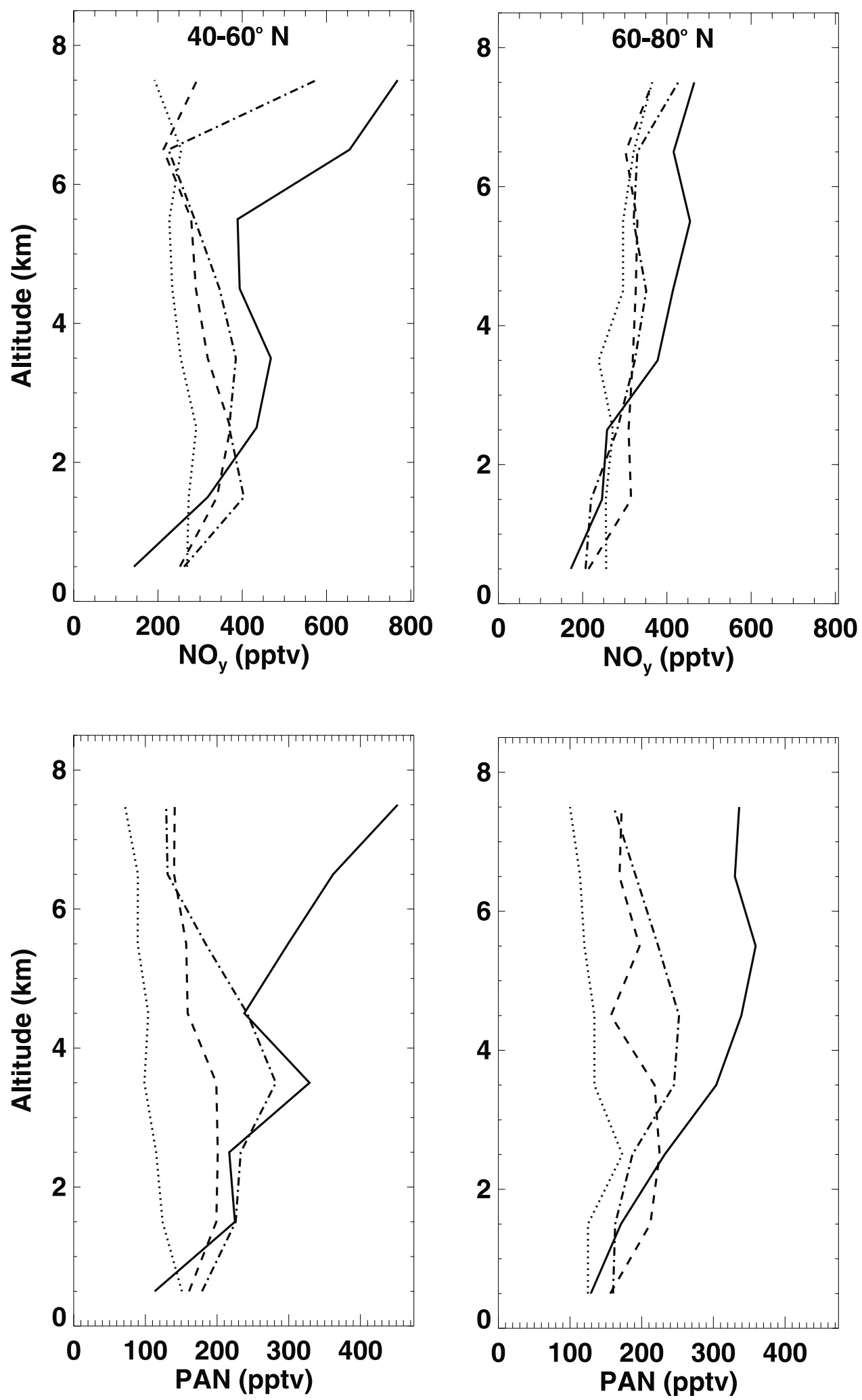

Figure 15. Same as Figure 1 but for $\mathrm{NO}_{y}, \mathrm{PAN}$, and $\mathrm{DNO}_{y}\left(\equiv \mathrm{NO}_{y}-\left(\mathrm{NO}+\mathrm{NO}_{2}+\mathrm{PAN}+\mathrm{PPN}+\right.\right.$ $\left.\mathrm{HNO}_{3}+2 \mathrm{~N}_{2} \mathrm{O}_{5}+\mathrm{HNO}_{4}\right)$ ). Medians of $\mathrm{DNO}_{y}$ for March and April are calculated mostly from a minimum of 10 data points. The data counts of $\mathrm{DNO}_{y}$ per altitude bin are less in February and May.

position in remote marine regions and lower latitudes contributes to the seasonal variability of ozone.

[36] The seasonal increases of $\mathrm{NO}$ and primary $\mathrm{HO}_{x}$ production (Figures 1 and 4) result in increasing chemical production of $\mathrm{O}_{3}$ (Figure 14). Figure 17 shows the budgets of $\mathrm{O}_{3}$ at mid and high latitudes. The model is not constrained by observed peroxides or $\mathrm{CH}_{2} \mathrm{O}$ because the restriction would reduce available data points so severely 


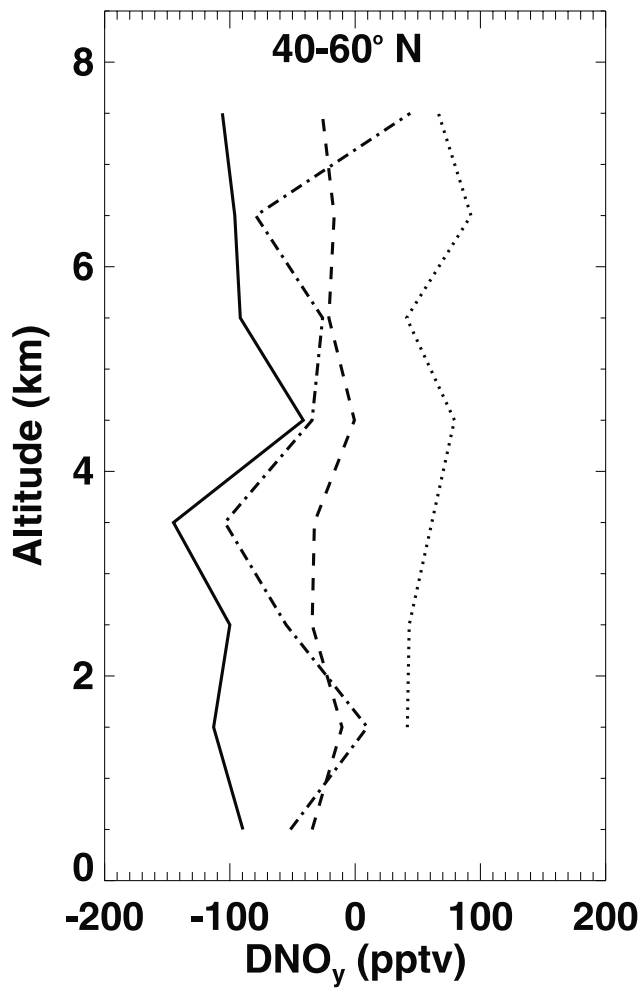

February April

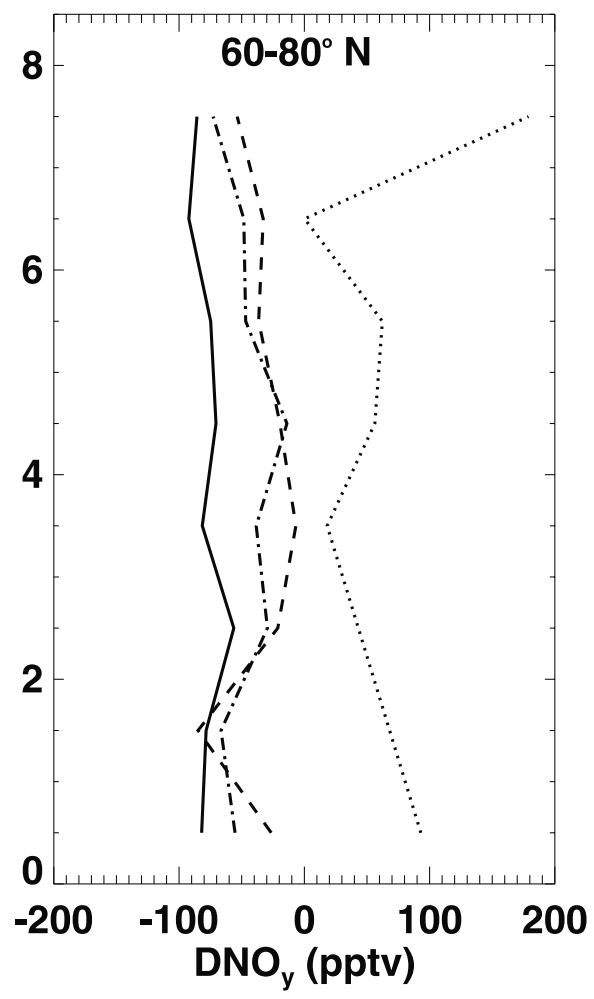

March

May

Figure 15. (continued)

that no statistically meaningful column budget can be obtained. The comparison of the simulations with and without the constraints shows that the effect of the scavenging loss of $\mathrm{H}_{2} \mathrm{O}_{2}$ is larger than those of higher than simulated ("excess") $\mathrm{CH}_{3} \mathrm{OOH}$ and $\mathrm{CH}_{2} \mathrm{O}$ concentrations in the observations. The resulting effects are similar (10$20 \%$ overestimates) for $\mathrm{O}_{3}$ production, loss, and net production (loss).

[37] Figure 17 shows the rapid increase of $\mathrm{O}_{3}$ production throughout the spring. The increase is more rapid at high latitudes (by a factor of 2-3 per month) than at midlatitudes (decreasing from a factor of 2 in February-March to $50 \%$ in April-May). By May, $\mathrm{O}_{3}$ column production rates $(0-8 \mathrm{~km})$ are $3.2 \times 10^{11}$ and $2.3 \times 10^{11} \mathrm{~cm}^{-2} \mathrm{~s}^{-1}$ for mid and high latitudes, respectively. About $70 \%$ of $\mathrm{O}_{3}$ production is due to the reaction of $\mathrm{HO}_{2}$ and $\mathrm{NO}$, and the rest is by the reactions of $\mathrm{NO}$ with $\mathrm{CH}_{3} \mathrm{O}_{2}$ and other organic peroxy radicals. The source from the reactions of $\mathrm{NO}$ and other organic peroxy radicals are significant compared to that from the reaction of $\mathrm{NO}$ and $\mathrm{CH}_{3} \mathrm{O}_{2}$ in early spring. The relative strengths of the two sources changes from 1:1 (1:2) in February to 1:3 (1:4) in May at high (mid) latitudes, reflecting the decrease of NMHCs with season (Figure 1). Our rate estimates are less than those calculated by Cantrell et al. [2002]; the former values are 24-hour averages while the latter ones are instantaneous rates at the time of the observations.

[38] The ozone budget at midlatitudes can be compared with the estimates for the western north Pacific $\left(30^{\circ}-50^{\circ} \mathrm{N}\right)$ in February-March (1994) by Crawford et al. [1997]. They found much larger column $\mathrm{O}_{3}$ production $\left(10.5 \times 10^{10}\right.$ $\left.\mathrm{cm}^{-2} \mathrm{~s}^{-1}\right)$ than loss $\left(3.8 \times 10^{10} \mathrm{~cm}^{-2} \mathrm{~s}^{-1}\right)$. Their production rate is similar to our estimate for March but their loss rate is similar to our estimate in February. As a result, their estimated column net production is much larger than our estimate. The discrepancy is due in part to higher $\mathrm{O}_{3}$ concentrations ( $\sim 20 \mathrm{ppbv}$ ) during TOPSE. One important similarity between the two studies is that the lower free troposphere $(1-4 \mathrm{~km})$ is a significant region of net $\mathrm{O}_{3}$ production. Crawford et al. [1997] attributed the enhanced $\mathrm{O}_{3}$ production at these altitudes to continental outflow to the western Pacific.

[39] The dominant role that $\mathrm{HO}_{2}$ plays in $\mathrm{O}_{3}$ loss rates is shown in Figure 18. The largest loss of $\mathrm{O}_{3}$ in the tropical and subtropical regions is due to photolysis of $\mathrm{O}_{3}$ and the subsequent reaction of $\mathrm{O}\left({ }^{1} \mathrm{D}\right)$ and $\mathrm{H}_{2} \mathrm{O}$ [e.g., Davis et al., 1996; Jacob et al., 1996]. In comparison, during TOPSE the largest loss of $\mathrm{O}_{3}$ is from the reaction of $\mathrm{O}_{3}$ and $\mathrm{HO}_{2}$. At midlatitudes, that loss accounts for $70 \%$ of the total $\mathrm{O}_{3}$ loss in February and a smaller 45\% in May. Kotchenruther et al. [2001] reported a fraction of about $60 \%$ in April over the north eastern Pacific. The fractional contribution by the reaction of $\mathrm{O}_{3}$ and $\mathrm{HO}_{2}$ at high latitudes decreases from $90 \%$ in February to $70 \%$ in May. The highest contribution by the reaction of $\mathrm{O}\left({ }^{1} \mathrm{D}\right)$ and $\mathrm{H}_{2} \mathrm{O}$ is $35 \%$ at midlatitudes in May. The small fractional contribution to $\mathrm{O}_{3}$ loss by the reaction of $\mathrm{O}\left({ }^{1} \mathrm{D}\right)$ and $\mathrm{H}_{2} \mathrm{O}$ reflects much drier air and less solar insolation over the TOPSE region compared to the lower latitudes. The crucial role played by $\mathrm{HO}_{2}$ in both $\mathrm{O}_{3}$ production and loss explains the similar sensitivities of these variables to a change in the $\mathrm{HO}_{x}$ source. 

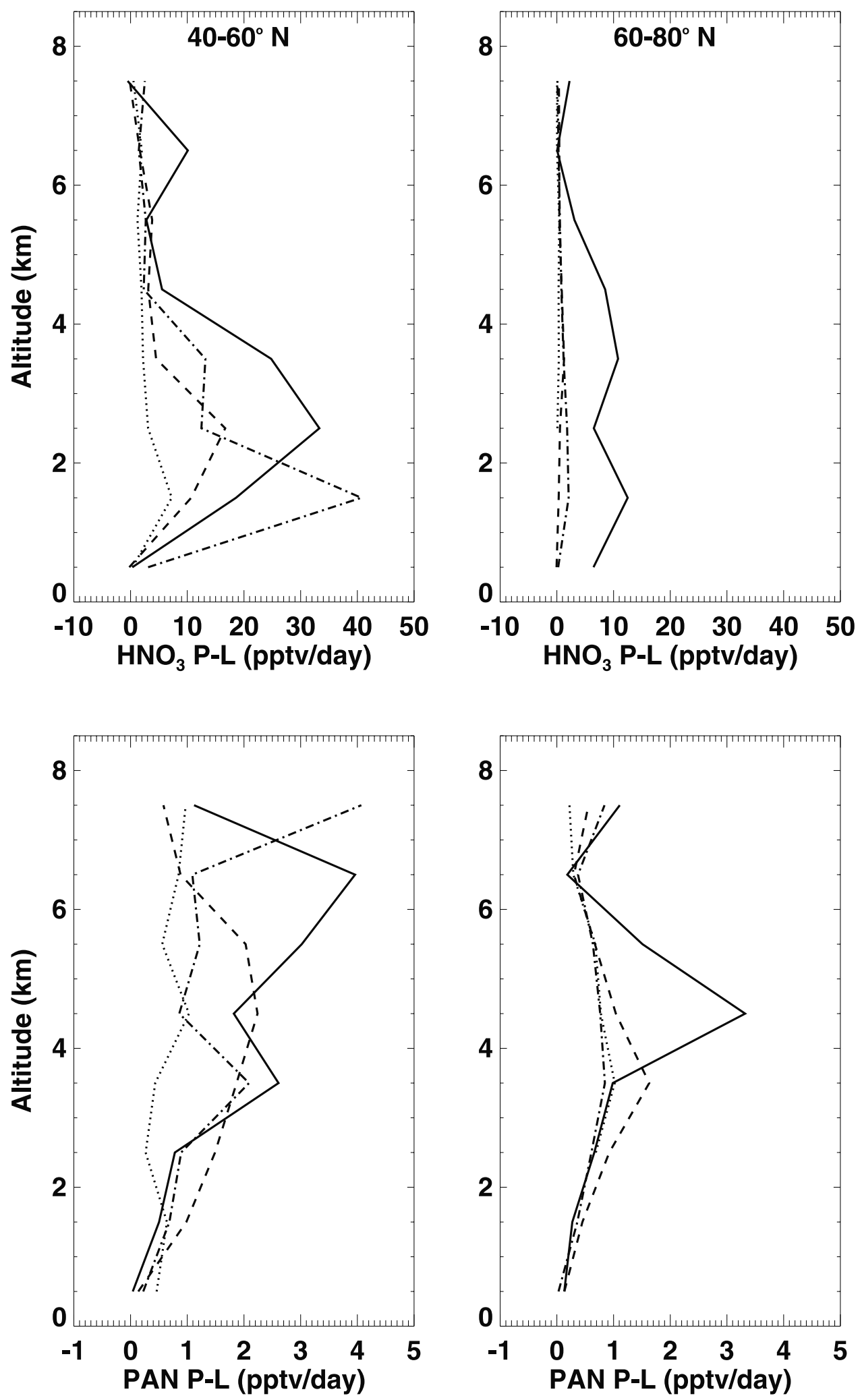

February April

March May

Figure 16. Same as Figure 1 but for simulated 24-hour average net production rates of $\mathrm{HNO}_{3}$ and PAN. The model is constrained by observed $\mathrm{HNO}_{3}$ and PAN concentrations. 

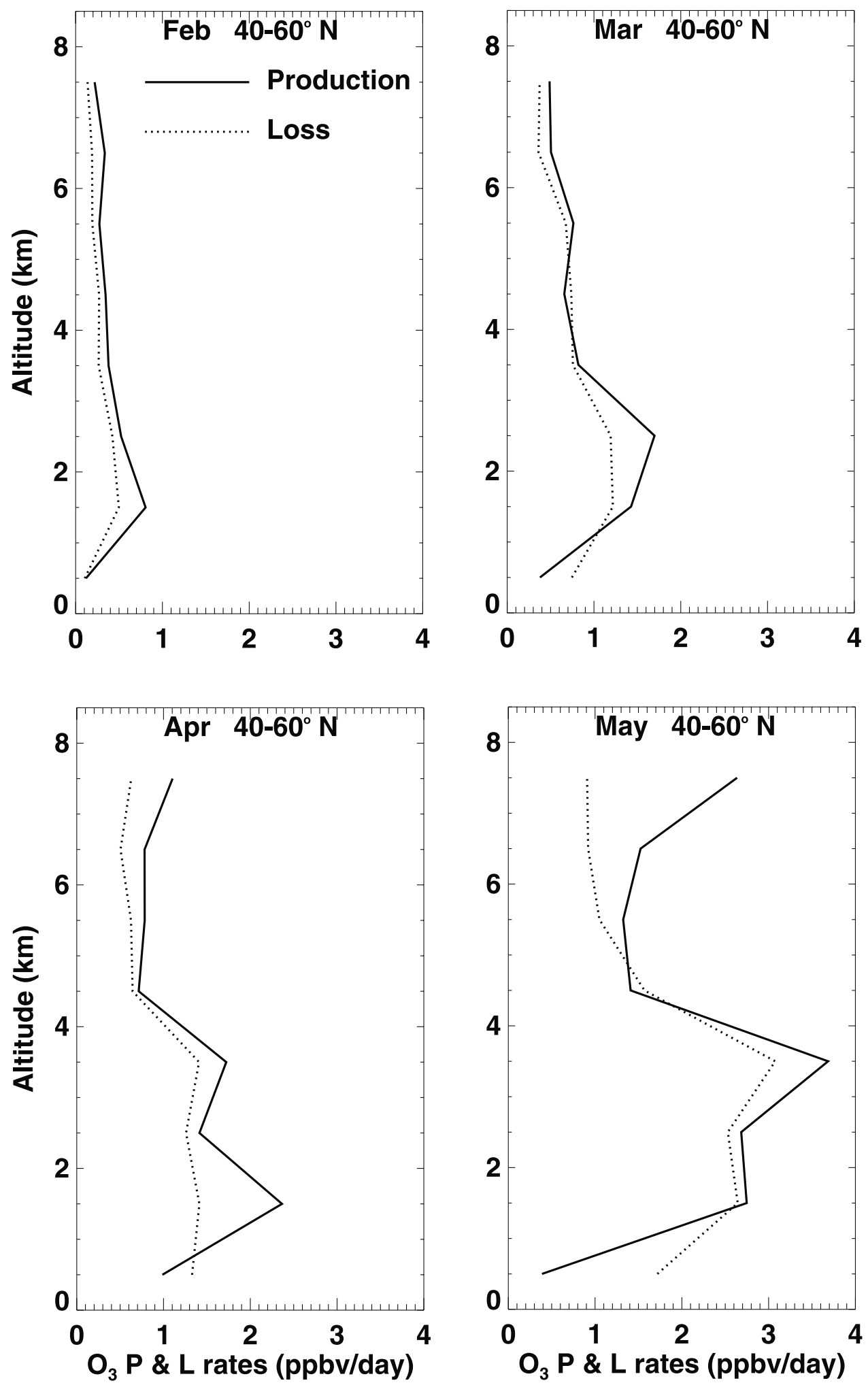

Figure 17. Simulated monthly medians of 24-hour average $\mathrm{O}_{3}$ production and loss rates as a function of altitude at mid and high latitudes. A median value plotted represents a minimum of 10 data points. The column $(0-8 \mathrm{~km}) \mathrm{O}_{3}$ production rates at mid (high) latitudes are $6.3(0.8), 14(2.7), 21(8.0)$, and $32(23)$ $\times 10^{10} \mathrm{~cm}^{-2} \mathrm{~s}^{-1}$ for February, March, April, and May, respectively. The corresponding loss rates are 4.4 $(0.9), 13(2.7), 17(9.0)$, and $31(20) \times 10^{10} \mathrm{~cm}^{-2} \mathrm{~s}^{-1}$. 

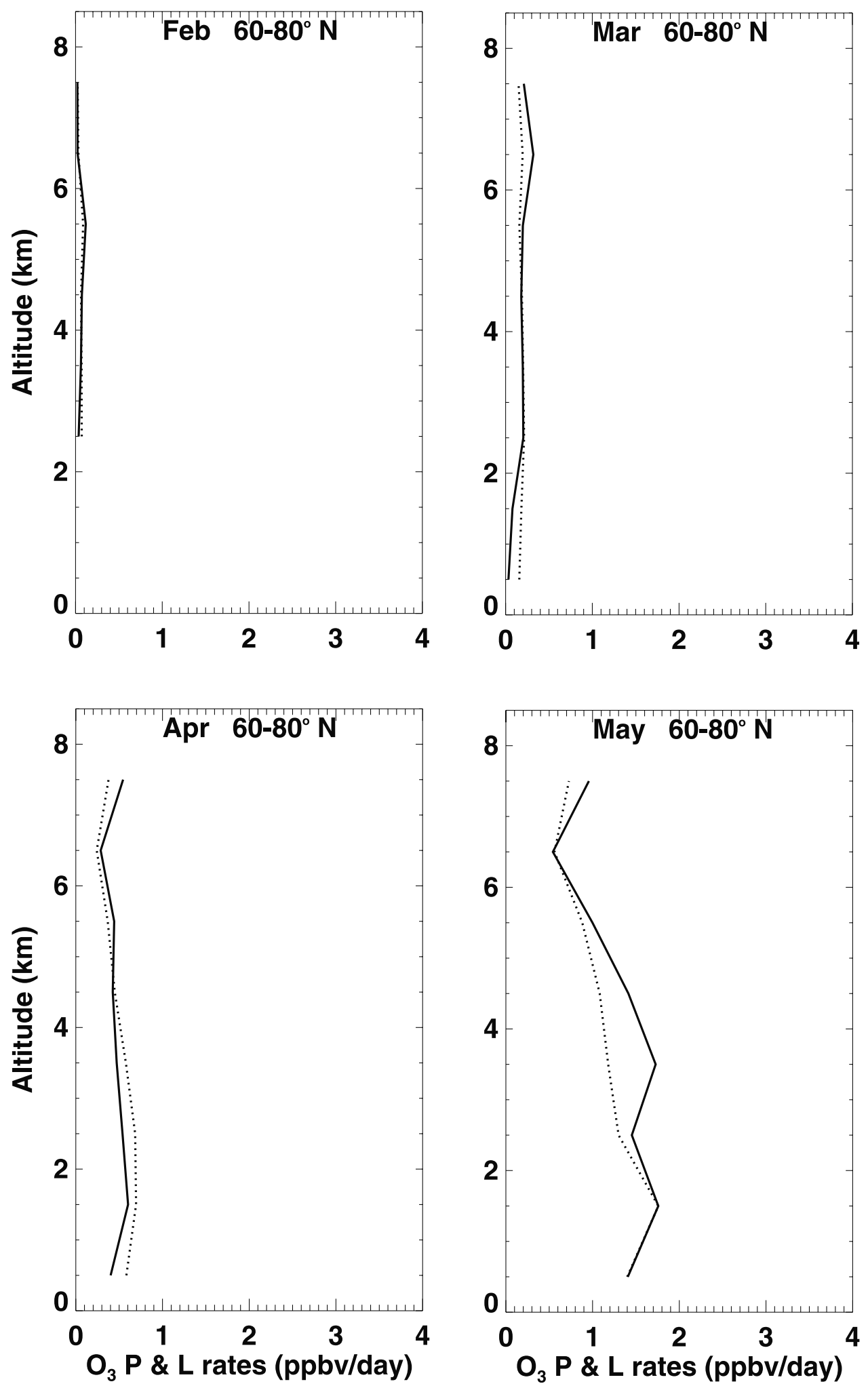

Figure 17. (continued)

[40] The relatively small loss of $\mathrm{O}_{3}$ by the reaction of $\mathrm{O}\left({ }^{1} \mathrm{D}\right)$ and $\mathrm{H}_{2} \mathrm{O}$ helps limit $\mathrm{O}_{3}$ loss at northern mid and high latitudes in spring, resulting in a net chemical production of $\mathrm{O}_{3}$ at midlatitudes during TOPSE. At midlatitudes, the net column chemical production is $2 \times 10^{10}, 1 \times 10^{10}, 4 \times$ $10^{11}$, and $1 \times 10^{11} \mathrm{~cm}^{-2} \mathrm{~s}^{-1}$ for February, March, April, and May respectively. The corresponding values at high latitudes are $-6 \times 10^{8},-4 \times 10^{9},-1 \times 10^{10}$, and $3 \times 10^{10}$ $\mathrm{cm}^{-2} \mathrm{~s}^{-1}$. The net loss in February-April at high latitudes reflects the low $\mathrm{NO}_{x}$ concentrations $(<5$ pptv below $5 \mathrm{~km})$ in the region (Figure 1). The net chemical production or loss is only $3-20 \%$ of the column $\mathrm{O}_{3}$ production or loss rate at 

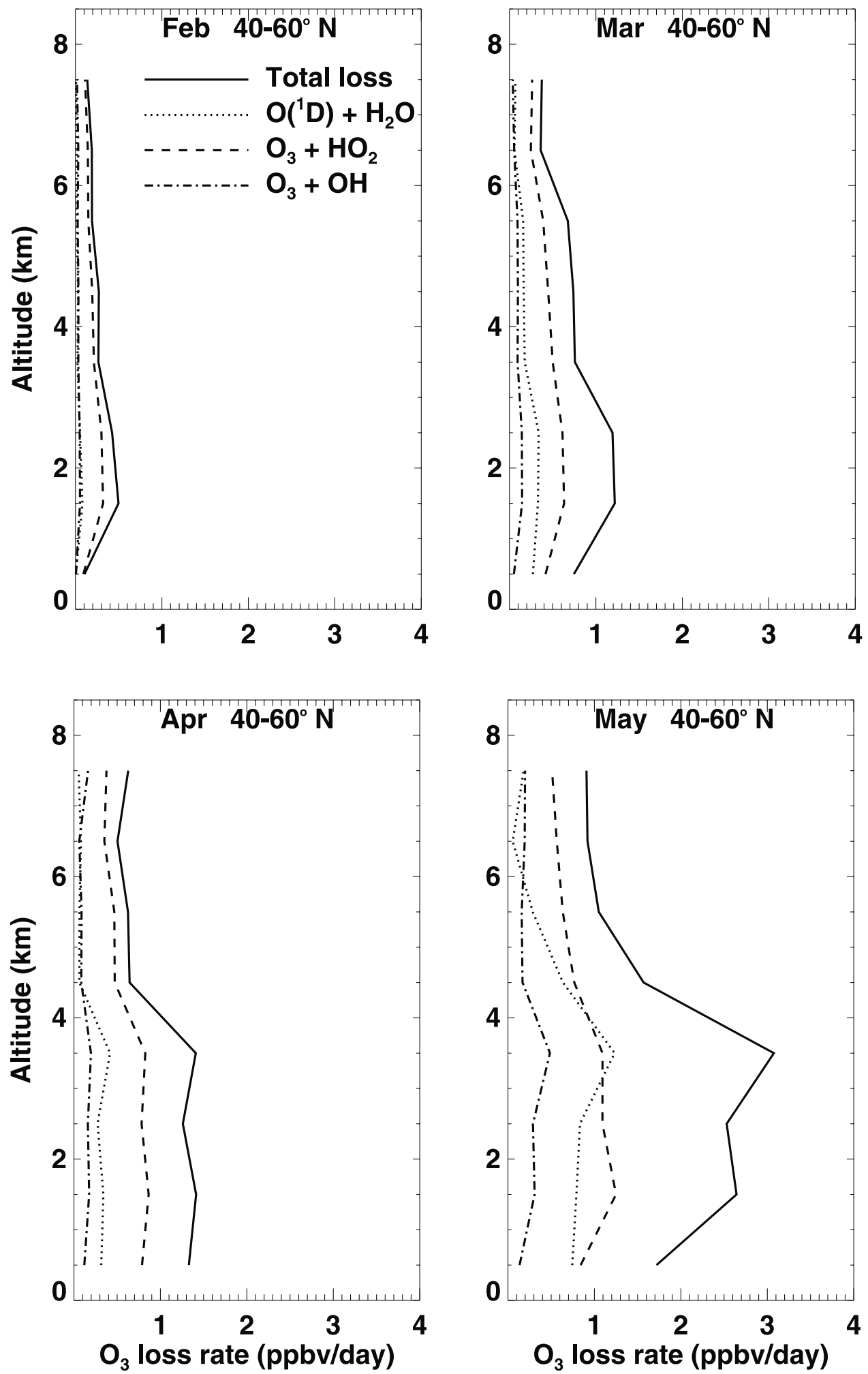

Figure 18. Same as Figure 17 but for simulated 24-hour average loss rates of $\mathrm{O}_{3}$ from various pathways.

0-8 km. The combination of high NO concentrations and low $\mathrm{H}_{2} \mathrm{O}$ content leads to net $\mathrm{O}_{3}$ production at high altitudes. Including the net $\mathrm{O}_{3}$ production in the region between $8 \mathrm{~km}$ and the tropopause will further increase the estimated net chemical production of $\mathrm{O}_{3}$.
[41] Figure 19 shows that the median column $\mathrm{O}_{3}$ concentration (defined as column moles of $\mathrm{O}_{3}$ /column moles of air) at midlatitudes is highest in April and that the most rapid $\mathrm{O}_{3}$ increase occurs in March-April, a period when the springtime $\mathrm{O}_{3}$ maxima were observed at lower altitudes at 

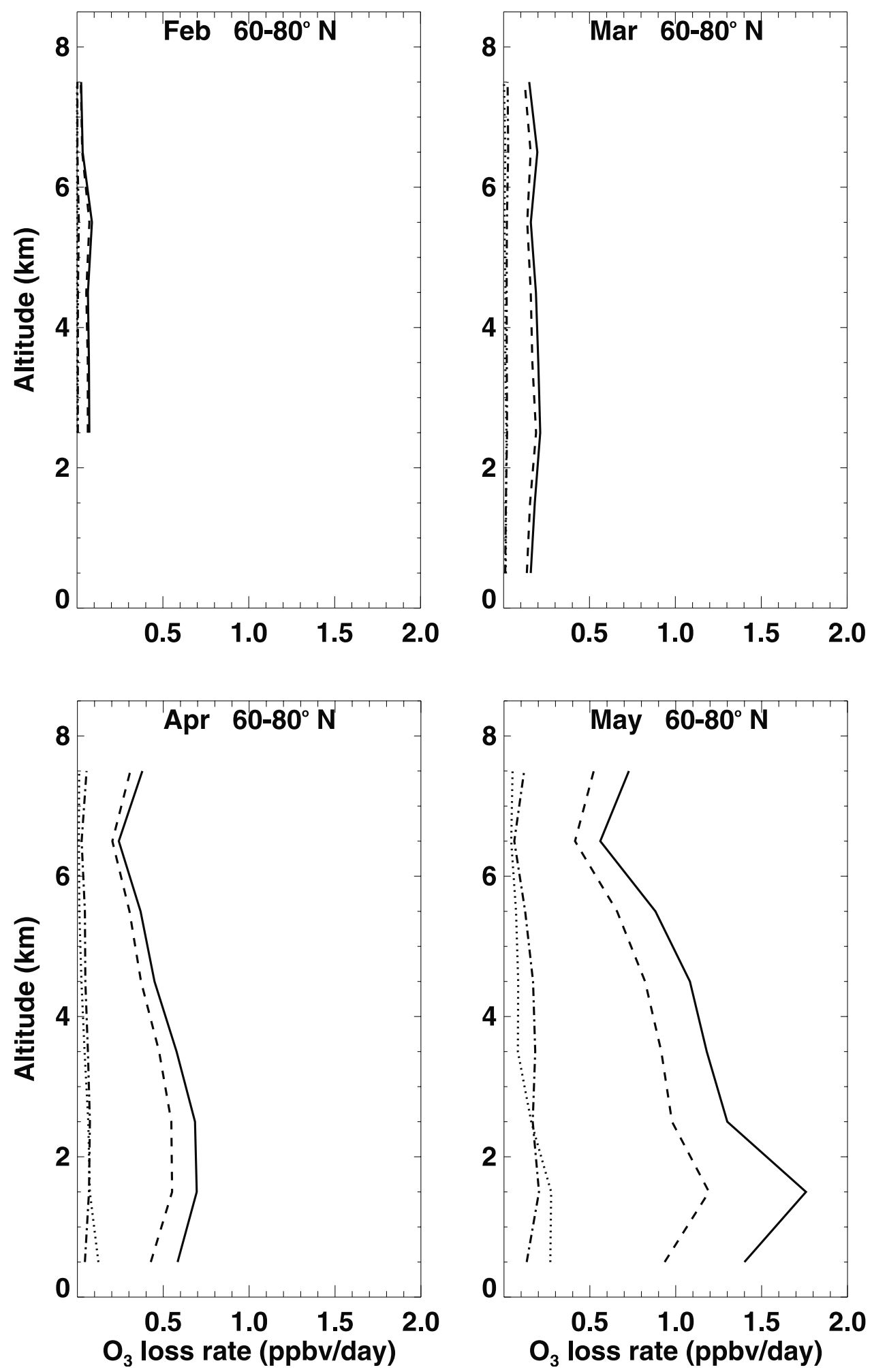

Figure 18. (continued)

mid and high latitudes [e.g., Logan, 1985; Levy et al., 1985]. The estimated net $\mathrm{O}_{3}$ production is also largest in April. In contrast, at high latitudes during TOPSE, column $\mathrm{O}_{3}$ concentrations continue to increase from February to May and there is an estimated chemical loss of $\mathrm{O}_{3}$ from February to April. To illustrate the different effects of in situ net $\mathrm{O}_{3}$ chemical production (loss) on column $\mathrm{O}_{3}$ concentrations at mid and high latitudes, we show in Figure 19 the column concentrations of $\mathrm{O}_{3}$ for March, April, and May if in situ chemistry is the only factor influencing the concentrations (see also the figure caption). The estimated column $\mathrm{O}_{3}$ at midlatitudes does not show a maximum in April 

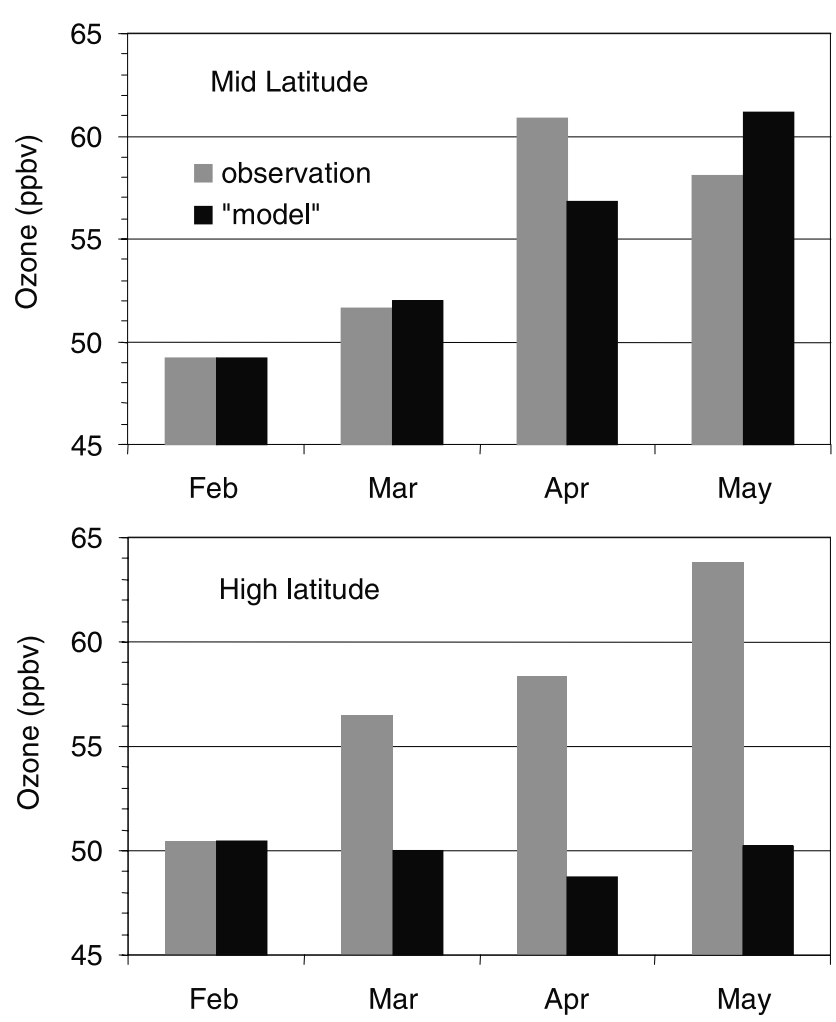

Figure 19. Observed median $\mathrm{O}_{3}$ column mixing ratios as a function of month at mid and high latitudes. For "modeled" column mixing ratios, we start from the observed February values on February 14 and compute the subsequent mixing ratios in the middle of March, April, and May using simulated monthly medians of 24 -hour average net production (loss) rates.

because the in situ chemical production is still larger than loss in May. Nonetheless, the estimated concentrations reach the observed levels at midlatitudes. In comparison, the estimated $\mathrm{O}_{3}$ concentrations at high latitudes remain at about $50 \mathrm{ppbv}$ due to the relatively small net production or loss in that region, whereas the observed column mixing ratio increases by $15 \mathrm{ppbv}$.

[42] In situ chemistry alone cannot explain the observed springtime $\mathrm{O}_{3}$ maxima at northern mid and high latitudes; transport plays an important role. Wang et al. [1998] tagged $\mathrm{O}_{3}$ transported from the stratosphere and that produced in different regions of the troposphere in a global 3-D chemistry and transport model. They found that $\mathrm{O}_{3}$ from the stratosphere peaked in late winter and early spring whereas $\mathrm{O}_{3}$ produced from the troposphere peaked in late spring and early summer. Both sources are important in reproducing the observed springtime $\mathrm{O}_{3}$ maxima at remote northern mid and high latitude sites in their model. Yienger et al. [1999] emphasized the role played by the net $\mathrm{O}_{3}$ chemical production at midlatitudes, which we find to be important for the TOPSE region. Their simulated net chemical $\mathrm{O}_{3}$ production $(2-10 \mathrm{~km})$ at midlatitudes peaks in March, one month earlier than we find for the TOPSE region. The two results, however, cannot be directly compared because their results include all regions at $30^{\circ}-60^{\circ} \mathrm{N}$. In our current work, we focused only on the effects of in situ chemical production and loss during TOPSE. Detailed analysis of tropospheric and stratospheric $\mathrm{O}_{3}$ transport into the TOPSE region is presented by Allen et al. [2002], Browell et al. [2002], Dibb et al. [2002], L. K. Emmons et al. (The budget of tropospheric ozone during TOPSE from two CTMs, submitted to Journal of Geophysical Research, 2002), and Y. Wang et al. (Intercontinental transport of pollution manifested in the seasonal trend of springtime $\mathrm{O}_{3}$ at northern mid and high latitudes, submitted to Science, 2002).

\section{Conclusions}

[43] Measurements were made onboard the NCAR/NSF C-130 aircraft in February-May during the TOPSE experiment at northern mid and high latitudes. The temporal and spatial span of the measurements allows for analysis of the rapid transition of photochemistry in springtime using a photochemical model. We have focused our work on photochemical factors driving $\mathrm{HO}_{x}$ and $\mathrm{O}_{3}$ chemistry.

[44] The continuously decreasing concentrations of NMHCs through spring, due in part to increasing $\mathrm{OH}$ oxidation, contrast to the observed increase in $\mathrm{O}_{3}$ and $\mathrm{NO}$ concentrations. Both trends favor partitioning of $\mathrm{HO}_{x}$ toward $\mathrm{OH}$. Photochemical activity as measured by the sources of $\mathrm{HO}_{x}$ increases rapidly at mid and high latitudes with season. The primary driving force for radical chemistry is photolysis of $\mathrm{O}_{3}$ and the subsequent reaction of $\mathrm{O}\left({ }^{1} \mathrm{D}\right)$ and $\mathrm{H}_{2} \mathrm{O}$, which benefits not only from the increasing solar insolation but higher $\mathrm{H}_{2} \mathrm{O}$ content of the warming air. The concentrations of total peroxy radicals rise accordingly; observed and simulated concentrations are in good agreement.

[45] One feature that sets TOPSE apart from the other tropospheric field experiments is the observations of low $\mathrm{H}_{2} \mathrm{O}_{2}$ concentrations (by a factor of 2-10) compared to model estimates. The loss of $\mathrm{HO}_{x}$ required to match observed $\mathrm{H}_{2} \mathrm{O}_{2}$ concentrations in the model implies a loss of $20-30 \%$ and $10-20 \%$ in $\mathrm{OH}$ concentrations and $\mathrm{O}_{3}$ production, respectively. The timescale of scavenging by rainout, calculated from the observed $\mathrm{HNO}_{3}$ concentrations, increases from about 1 week at midlatitudes to $2-4$ weeks at high latitudes in agreement with previous estimates. However, the required scavenging loss frequency of $\mathrm{H}_{2} \mathrm{O}_{2}$ is much faster. Furthermore, it increases rapidly with season. The estimated timescales of $\mathrm{H}_{2} \mathrm{O}_{2}$ against scavenging loss in May are about half a day and 1 day at mid and high latitudes, respectively. If the scavenging loss of $\mathrm{H}_{2} \mathrm{O}_{2}$ were mostly due to its oxidation of $\mathrm{SO}_{2}$ in droplets, the oxidation would imply a sulfate deposition rate of $>2.5 \mathrm{~g} \mathrm{~S}$ $\mathrm{m}^{-2} \mathrm{yr}^{-1}$, an order of magnitude larger than previous estimates. Unknown mechanisms need to be invoked to explain the rapid loss of $\mathrm{H}_{2} \mathrm{O}_{2}$ during TOPSE.

[46] Whereas observed and simulated $\mathrm{CH}_{3} \mathrm{OOH}$ concentrations show good agreement in April and May at high latitudes, they differ significantly in March at midlatitudes. The model shows generally decreasing $\mathrm{CH}_{3} \mathrm{OOH}$ concentrations with altitudes; an opposite trend is observed in March at midlatitudes. Transport processes alone do not appear to explain the observed profile of increasing $\mathrm{CH}_{3} \mathrm{OOH}$ concentrations with altitude. Using observed in place of simulated $\mathrm{CH}_{3} \mathrm{OOH}$ concentrations in the model tends to increase $\mathrm{CH}_{2} \mathrm{O}$ concentrations at high altitudes. The 
relative enhancement is significant $(50-100 \%$ or $20-30$ pptv) at $6-8 \mathrm{~km}$ in March.

[47] Observed and simulated $\mathrm{CH}_{2} \mathrm{O}$ concentrations show better agreement than in previous northern midlatitude missions. The consistent underestimates by the model in the upper troposphere at high altitudes imply a large source of $\mathrm{HO}_{x}$ (by $\mathrm{CH}_{2} \mathrm{O}$ photolysis) in the region. Likely sources are transport from midlatitudes or heterogeneous conversion from methanol or other species, in which case photolysis of $\mathrm{CH}_{2} \mathrm{O}$ boosts the primary production of $\mathrm{HO}_{x}$. This additional $\mathrm{HO}_{x}$ source increases the total $\mathrm{HO}_{x}$ production by $50-200 \%$ at $6-8 \mathrm{~km}$ at high latitudes resulting in $10-50 \%$ increases in $\mathrm{OH}$ concentrations and $\mathrm{O}_{3}$ production.

[48] The source of $\mathrm{NO}_{x}$ does not appear to come from the decomposition of long-lived reactive nitrogen species, among which PAN is the most dominant component. The tropospheric burden of $\mathrm{NO}_{y}$ at mid and high latitudes continues to grow throughout the spring. This seasonal increase is clearly evident in the free troposphere. The seasonality is less clearly defined at $0-3 \mathrm{~km}$. The concentrations of $\mathrm{NO}_{y}$ near the surface decrease from February to May (particularly at high latitudes) as those of NMHCs. Similar difference of the seasonal trend with altitude is observed for PAN except that the seasonal peak of PAN near the surface shifts toward April. Budget studies of PAN and $\mathrm{HNO}_{3}$ show a net loss of $\mathrm{NO}_{x}$ to these reservoirs species throughout the spring. There appears to be a seasonal shift in the difference between $\mathrm{NO}_{y}$ and the sum of individual components $\left(\mathrm{NO}+\mathrm{NO}_{2}+\right.$ PAN + $\mathrm{PPN}+\mathrm{HNO}_{3}+2 \mathrm{~N}_{2} \mathrm{O}_{5}+\mathrm{HNO}_{4}$ ), among which $\mathrm{NO}_{2}$, $\mathrm{N}_{2} \mathrm{O}_{5}$, and $\mathrm{HNO}_{4}$ are computed in the model. The former is larger in February but becomes progressively smaller than the latter in later months. The shift shows little altitude dependence.

[49] The production of $\mathrm{O}_{3}$ in the TOPSE region increases substantially from February to May, by factors of 5 and 25 respectively at mid and high latitudes. The rapid increase is driven by increasing primary $\mathrm{HO}_{x}$ production and $\mathrm{NO}$ concentrations. The latter is due in part to the increasing partitioning of $\mathrm{NO}_{x}$ toward $\mathrm{NO}$ with more intense solar irradiation in spring. Ozone production is less sensitive to an increase in the primary $\mathrm{HO}_{x}$ production than that in $\mathrm{NO}$ concentrations. However, the former factor, driven by the reaction of $\mathrm{O}\left({ }^{1} \mathrm{D}\right)$ and $\mathrm{H}_{2} \mathrm{O}$, increases more rapidly than the latter. Ozone photochemistry is in the $\mathrm{NO}_{x}$-limited regime during TOPSE.

[50] Peroxy radicals generally play the pivotal role in $\mathrm{O}_{3}$ production. The reaction of $\mathrm{HO}_{2}$ and $\mathrm{NO}$ accounts for about $70 \%$ of the total production. The contribution by the reaction of higher $\left(\geq C_{2}\right)$ organic peroxy radicals and $\mathrm{NO}$ is as large as that by the reaction of $\mathrm{CH}_{3} \mathrm{O}_{2}$ and $\mathrm{NO}$ in early spring, reflecting the high concentrations of NMHCs at the time. Its relative importance decreases toward summer. During TOPSE, $\mathrm{HO}_{2}$ is also the major component in $\mathrm{O}_{3}$ loss through the reaction of $\mathrm{HO}_{2}$ and $\mathrm{O}_{3}$. The loss pathway accounts for $45-70 \%$ and $70-90 \%$ of the total loss at mid and high latitudes, respectively. The loss pathway by photolysis of $\mathrm{O}_{3}$ and the subsequent reaction of $\mathrm{O}\left({ }^{1} \mathrm{D}\right)$ and $\mathrm{H}_{2} \mathrm{O}$, which dominates $\mathrm{O}_{3}$ loss at lower latitudes, is highest $(35 \%)$ at midlatitudes in May. As a result, the sensitivities of $\mathrm{O}_{3}$ production and loss to a change in the primary $\mathrm{HO}_{x}$ production are similar.
[51] We find net in situ column $\mathrm{O}_{3}$ chemical production $(0-8 \mathrm{~km})$ at midlatitudes, $2 \times 10^{10}, 1 \times 10^{10}, 4 \times 10^{11}$, and $1 \times 10^{11} \mathrm{~cm}^{-2} \mathrm{~s}^{-1}$ for February, March, April, and May respectively. In contrast, there is a net in situ chemical loss of $\mathrm{O}_{3}$ at high latitudes except in May. The corresponding values at high latitudes are $-6 \times 10^{8},-4 \times 10^{9},-1 \times$ $10^{10}$, and $3 \times 10^{10} \mathrm{~cm}^{-2} \mathrm{~s}^{-1}$. The difference reflects lower NO concentrations and solar irradiation at high latitudes. At midlatitudes, the lower free troposphere $(1-4 \mathrm{~km})$ in addition to the upper troposphere is a region of significant net $\mathrm{O}_{3}$ production. The observed $\mathrm{O}_{3}$ column $(0-8 \mathrm{~km})$ shows a peak in April at midlatitudes but continues to increase from February to May at high latitudes. In situ chemistry alone cannot explain the observed seasonality of column $\mathrm{O}_{3}$ during TOPSE. Nonetheless, in situ net chemical production is a significant contributor to the observed $\mathrm{O}_{3}$ increase at midlatitudes, where both net $\mathrm{O}_{3}$ production and column concentration peak in April. Net transport from other tropospheric regions or the stratosphere is necessary to explain the observed seasonal increase of column $\mathrm{O}_{3}$ at high latitudes.

[52] Acknowledgments. We thank Luca Cinquini and Lousia Emmons at NCAR for their excellent work in data management and for sending us various data products. We also thank Anthony Wimmers and Jennie Moody at the University of Virginia for providing their backtrajectory analysis. The operation of C-130 aircraft during TOPSE was managed by the Research Aviation Facility of NCAR. This work is supported by the National Science Foundation (grant ATM-0000337).

\section{References}

Allen, J. J., J. E. Dibb, K. E. Pickering, and B. A. Ridley, An estimate of the stratospheric contribution to springtime tropospheric ozone maxima using TOPSE measurements and Beryllium-7 simulations, J. Geophys. Res., doi:10.1029/2001JD001428, in press, 2002. [printed 108(D8), 2003]

Atkinson, R., et al., Evaluated kinetic and photochemical data for atmospheric chemistry, J. Phys. Chem. Ref. Data, 26, 1329-1499, 1997.

Ayers, G. P., R. W. Gillett, H. Granek, C. de Serves, and R. A. Cox, Formaldehyde production in clean marine air, Geophys. Res. Lett., 24, 401-404, 1997.

Balkanski, Y. J., D. J. Jacob, G. M. Gardner, W. M. Graustein, and K. K. Turekian, Transport and residence times of continental aerosols inferred from a global 3-dimensional simulation of ${ }^{210} \mathrm{~Pb}$, J. Geophys. Res., 98, 20,573-20,586, 1993

Blake, N. J., D. R. Blake, B. C. Sive, A. S. Katzenstein, S. Meinardi, O. W. Wingenter, E. L. Atlas, F. Flocke, B. A. Ridley, and F. S. Rowland, The seasonal evolution of NMHCs and light alkyl nitrates at mid to high northern latitudes during TOPSE, J. Geophys. Res., doi:10.1029/2001JD001467, in press, 2002. [printed 108(D8), 2003]

Bottenheim, J. W., and M. F. Shepherd, C2-C6 hydrocarbon measurements at 4 rural locations across Canada, Atmos. Environ., 29, 647-664, 1995.

Bradshaw, J., et al., Observed distributions of nitrogen oxides in the remote free troposphere from the NASA Global Tropospheric Experiment programs, Rev. Geophys., 38, 61-116, 2000.

Browell, E., et al., Ozone, aerosol, potential vorticity, and trace gas trends observed at high latitudes over Northern America from February to May 2000, J. Geophys. Res., doi:10.1029/2001JD001390, in press, 2002. [printed 108(D4), 2003]

Cantrell, C., et al., Steady state free radical budgets and ozone photochemistry during TOPSE, J. Geophys. Res., doi:10.1029/2002JD002198, in press, 2002. [printed 108(D8), 2003]

Carpenter, L. J., et al., Oxidized nitrogen and ozone production efficiencies in the springtime free troposphere over the Alps, J. Gephys. Res., 105, $14,547-14,559,2000$.

Chen, G., et al., An assessment of $\mathrm{HO}_{\mathrm{x}}$ chemistry in the tropical Pacific boundary layer: Comparison of observations with model simulations during PEM Tropics A, J. Atmos. Chem., 38, 317-344, 2001.

Christensen, L. E., M. Okumura, S. P. Sander, R. J. Salawitch, G. C. Toon, B. Sen, J.-F. Blavier, and K. W. Jucks, Kinetics of $\mathrm{HO}_{2}+\mathrm{HO}_{2} \rightarrow \mathrm{H}_{2} \mathrm{O}_{2}+$ $\mathrm{O}_{2}$ : Implications for Stratospheric $\mathrm{H}_{2} \mathrm{O}_{2}$, Geophys. Res. Lett., 29(9), 1299, doi:10.1029/2001GL014525, 2002. 
Crawford, J. H., et al., An assessment of ozone photochemistry in the extratropical western North Pacific: Impact of continental outflow during the late winter/early spring, J. Geophys. Res., 102, 28,469-28,487, 1997.

Crawford, J. H., et al., Assessment of upper tropospheric $\mathrm{HO}_{\mathrm{x}}$ sources, J. Geophys. Res., 104, 16,255-16,273, 1999.

Davis, D. D., et al., Assessment of the ozone photochemistry tendency in the western North Pacific as inferred from PEM-West A observations during the fall of 1991, J. Geophys. Res., 101, 2111-2134, 1996.

Davis, D. D., et al., Marine latitude/altitude $\mathrm{OH}$ distributions: Comparison of Pacific Ocean observations with models, J. Geophys. Res., 106 , 32,691-32,708, 2001.

DeMore, W. B., et al., Chemical Kinetics and Photochemical Data for Use in Stratospheric Modeling, JPL Publ. 97-4, 266 pp., Jet Propulsion Lab., Pasadena, Calif., 1997.

Dibb, J. E., R. W. Talbot, E. M. Scheuer, G. Seid, L. DeBell. B. Lefer, and B. A. Ridley, Stratospheric influence on the northern North American free troposphere during TOPSE: ${ }^{7} \mathrm{Be}$ as a stratospheric tracer, J. Geophys. Res. doi:10.1029/2001JD001347, in press, 2002. [printed 108(D4), 2003]

Fried, A., et al., Tunable diode laser measurements of formaldehyde during the TOPSE 2000 study: Distributions, trends, and model comparisons, J. Geophys. Res., doi:10.1029/2002JD002208, in press, 2002. [printed 108(D8), 2003]

Hoffmann, M. R., and J. O. Edwards, Kinetics of oxidation of sulfite by hydrogen peroxide in acidic solution, J. Phys. Chem., 79, 2096-2098, 1975

Honrath, R. E., and D. A. Jaffe, The seasonal cycle of nitrogen oxides in the Arctic troposphere at Barrow, Alaska, J. Geophys. Res., 97, 20,61520,630, 1992

Honrath, R. E., A. J. Hamlin, and J. T. Merrill, Transport of ozone precursors from the Arctic troposphere to the North Atlantic region, J. Geophys. Res. 101, 29,335-29,351, 1996.

Jacob, D. J., et al., The origin of ozone and $\mathrm{NO}_{\mathrm{x}}$ in the tropical troposphere: A photochemical analysis of aircraft observations over the South Atlantic Basin, J. Geophys. Res., 101, 24,235-24,250, 1996.

Jacob, D. J., B. D. Field, E. Jin, I. Bey, Q. Li, J. A. Logan, and R. M. Yantosca, Atmospheric budget of acetone, J. Geophys. Res., 107(D9), 4100, doi:10.1029/2001JD000694, 2002.

Jaeglé, L., et al., Ozone production in the upper troposphere and the influence of aircraft during SONEX: Approach of $\mathrm{NO}_{\mathrm{x}}$-saturated conditions, Geophys. Res. Lett., 26, 3081-3084, 1999.

Jaeglé, L., et al., Photochemistry of $\mathrm{HO}_{\mathrm{x}}$ in the upper troposphere at northern midlatitudes, J. Geophys. Res., 105, 3877-3892, 2000.

Jobson, B. T., et al., Measurements of C2-C6 hydrocarbons during the Polar Sunrise 1992 Experiment: Evidence for $\mathrm{Cl}$ atom and $\mathrm{Br}$ atom chemistry, J. Geophys. Res., 99, 25,355-25,368, 1994.

Kotchenruther, R. A., D. A. Jaffe, and L. Jaeglé, Ozone photochemistry and the role of peroxyacetyl nitrate in the springtime northeastern Pacific troposphere: Results from the Photochemical Ozone Budget of the Eastern Northern Pacific Atmosphere (PHOBEA) Campaign, J. Geophys. Res., 106, 28,731-28,742, 2001.

Langer, J., and H. Rodhe, A global three-dimensional model of the tropospheric sulfur cycle, J. Atmos. Chem., 13, 225-263, 1991

Levy, H., II, J. D. Mahlman, W. J. Moxim, and S. C. Liu, Tropospheric ozone: The role of transport, J. Geophys. Res., 88, 3753-3772, 1985.

Liu, S. C., M. Trainer, F. C. Fehsenfeld, D. D. Parrish, E. J. Williams, D. W. Fahey, G. Hubler, and P. C. Murphy, Ozone production in the rural troposphere and the implications for regional and global ozone distributions, J. Geophys. Res., 92, 10,463-10,482, 1987.

Liu, S. C., et al., A study of the photochemistry and ozone budget during the Mauna Loa Observatory Photochemistry Experiment, J. Geophys. Res., 97, 10,463-10,471, 1992.

Logan, J. A., Tropospheric ozone: Seasonal behavior, trends, and anthropogenic influence, J. Geophys. Res., 90, 10,463-10,482, 1985.
Logan, J. A., M. J. Prather, S. C. Wofsy, and M. B. McElroy, Tropospheric chemistry: A global perspective, J. Geophys. Res., 86, 7210-7254, 1981. McKeen, S. A., et al., Photochemical modeling of hydroxyl and its relationship to other species during the tropospheric $\mathrm{OH}$ photochemistry experiment, J. Geophys. Res., 102, 6467-6493, 1997.

Novelli, P. C., J. E. Collins Jr., R. C. Myers, G. W. Sachse, and H. E. Scheel, Re-evaluation of the NOAA/CMDL carbon monoxide reference scale and comparisons to CO reference gases at NASA-Langley and the Fraunhofer Institute, J. Geophys. Res., 99, 12,833-12,839, 1994.

Penkett, S. A., and K. A. Brice, The spring maximum in photo-oxidants in the Northern Hemisphere troposphere, Nature, 319, 655-657, 1986.

Prather, M. J., and D. J. Jacob, A persistent imbalance in $\mathrm{HO}_{x}$ and $\mathrm{NO}_{x}$ photochemistry of the upper troposphere driven by deep tropical convection, Geophys. Res. Lett., 24, 3189-3192, 1997.

Schultz, M., et al., On the origin of tropospheric ozone and $\mathrm{NO}_{x}$ over the tropical South Pacific, J. Geophys. Res., 104, 5829-5843, 1999.

Shetter, R. E., L. Cinquini, B. L. Lefer, S. R. Hall, and S. Madronich, Comparison of airborne measured and calculated spectral actinic flux and derived photolysis frequencies during the PEM Tropics B mission, J. Geophys. Res., 107, 8234, doi:10.1029/2001JD001320, 2002. [printed 108(D2), 2003]

Singh, H., et al., Distribution and fate of selected oxygenated organic species in the troposphere and lower stratosphere over the Atlantic, J. Geophys. Res., 105, 3795-3805, 2000

Talukdar, R. K., C. A. Longfellow, M. K. Gilles, and A. R. Ravishankara, Quantum yields of $\mathrm{O}\left({ }^{1} \mathrm{D}\right)$ in the photolysis of ozone between 289 and $329 \mathrm{~nm}$ as a function of temperature, Geophys. Res. Lett., 25, 143-146, 1998.

Tie, X., et al., Effect of sulfate aerosol on tropospheric $\mathrm{NO}_{\mathrm{x}}$ and ozone budgets: Model simulations and TOPSE evidence, J. Geophys. Res., doi:10.1029/2001JD001508, in press, 2002. [printed 108(D2), 2003]

Wang, Y., D. J. Jacob, and J. A. Logan, Global simulation of tropospheric $\mathrm{O}_{3}-\mathrm{NO}_{\mathrm{x}}$-hydrocarbon chemistry, 3, Origin of tropospheric ozone and effects of non-methane hydrocarbons, J. Geophys. Res., 103, 10,757$10,768,1998$

Wang, Y., S. C. Liu, H. Yu, S. Sandholm, T.-Y. Chen, and D. R. Blake, Influence of convection and biomass burning on tropospheric chemistry over the tropical Pacific, J. Geophys. Res., 105, 9321-9333, 2000.

Wang, Y., et al., Factors Controlling Tropospheric $\mathrm{O}_{3}, \mathrm{OH}, \mathrm{NO}_{\mathrm{x}}$, and $\mathrm{SO}_{2}$ over the Tropical Pacific during PEM-Tropics B, J. Geophys. Res., 106, 32,733-32,748, 2001

Yienger, J. J., A. A. Klonecki, H. Levy, W. J. Moxim, and G. R. Carmichael, An evaluation of chemistry's role in the winter-spring ozone maximum found in the northern midlatitude free troposphere, J. Geophys. Res., 104, 3655-3668, 1999.

Zanis, P., P. S. Monks, E. Schuepbach, and S. A. Penkett, The role of in situ photochemistry in the control of ozone during spring at the Jungfraujoch (3580 m asl): Comparison of model results with measurements, J. Atmos. Chem., 37, 1-27, 2000 .

E. Atlas, C. Cantrell, M. Coffey, F. Flocke, A. Fried, B. Lefer, B. Ridley, R. Shetter, J. Walega, A. Weinheimer, and B. Wert, National Center for Atmospheric Research, Boulder, CO, USA.

D. Blake and N. Blake, Department of Chemistry, University of California at Irvine, Irvine, CA, USA

G. Chen, D. Davis, and Y. Wang, School of Earth and Atmospheric Sciences, Georgia Institute of Technology, Atlanta, GA 30332-0340, USA. (ywang@eas.gatech.edu)

J. Dibb and R. Talbot, Institute for the Study of Earth, Oceans, and Space, University of New Hampshire, Durham, NH, USA

B. Heikes and J. Snow, Graduate School of Oceanography, University of Rhode Island, Narragansett, RI, USA. 